\title{
1 Lake area and volume variation in the endorheic basin of 2 the Tibetan Plateau from 1989 to 2019
}

3 Liuming Wang ${ }^{1,3}$, Junxiao Wang ${ }^{2,3}$, Mengyao $\mathrm{Li}^{1}$, Liping $\mathrm{Zhu}^{4}$, Xingong $\mathrm{Li}^{5}$

$4 \quad{ }^{1}$ Schoole of Geography and Ocean Science, Nanjing University, Nanjing, 210023, China

${ }^{2}$ Schoole of Public Administration, University of Finance \& Economics, Nanjing, 210023, China

${ }^{3}$ Laboratory of Coastal Zone Exploitation and Protection, Ministry of Natural Resource, Nanjing, Jiangsu, 210017, China

${ }^{4}$ Key Laboratory of Tibetan Environment Changes and Land Surface Processes (TEL), Institute of Tibetan Plateau Research (ITP), Chinese Academy of Sciences, Beijing 100101, China

${ }^{5}$ Department of Geography \& Atmospheric Science, University of Kansas, Lawrence, 66045, United States of America

Correspondence to: Junxiao Wang(wangjunxiao@nufe.edu.cn) and Xingong Li (lixi@ku.edu)

\begin{abstract}
The Tibetan Plateau, known as "the third pole of the Earth", is a region susceptible to climate change. With little human disturbance, lake storage changes serve as a unique indicator of climate change, but comprehensive lake storage data are rare in the region, especially for the lakes with an area less than $10 \mathrm{~km}^{2}$ which are the most sensitive to environmental changes. In this paper, we completed a census of annual lake volume change for 976 lakes larger than $1 \mathrm{~km}^{2}$ in the endorheic basin of the Tibetan Plateau (EBTP) during 1989-2019 using Landsat imagery and digital terrain models. Validation and comparison with several existing studies indicate that our data are more reliable. Lake volume in the EBTP exhibited a net increase of $193.45 \mathrm{~km}^{3}$ during the time period with an increasing rate of $6.45 \mathrm{~km}^{3}$ year $^{-1}$. In general, the larger the lake area, the greater the lake volume change, though there are some exceptions. Lakes with an area less than $10 \mathrm{~km}^{2}$ have more severe volume change whether decreasing or increasing. This research complements existing lake studies by providing a comprehensive and long-term lake volume change data for the region. The dataset is available on Zenodo (https://doi.org/10.5281/zenodo.5543615, Wang et al., 2021).
\end{abstract}

Keywords. Tibetan Plateau, Landsat, relative lake volume

\section{Introduction}

Alpine lakes are susceptible to climate change in arid and semi-arid endorheic watersheds (Williamson et al., 2009; Yao et al., 2018). One of the world's largest alpine lake groups are found in the Tibetan Plateau (TP) (Yang et al., 2017a), which, together with its surrounding regions, is often referred to as "the Third Pole of the Earth" (Qiu, 2008) and the "roof and the world" and provides vital water resources 
34 for more than a billion population in Asia and is a sensitive region undergoing rapid climate change

35 (Field, 2014).

36 With little human disturbance in the region, lake volume variation may serve as an important indicator

37 that reflects regional hydrologic system's responses to climate change (Boos and Kuang, 2010; Yang et

38 al., 2017b). In the past 50 years, the TP has undergone a much faster warming trend $\left(\sim 0.447^{\circ} \mathrm{C}\right.$ per

39 decade) than the global average $\left(0.15-0.20^{\circ} \mathrm{C}\right.$ per decade) (Hansen et al., 2010; Xu et al., 2008), which

40 posed inevitable impacts on the water budget of its alpine lakes (Lei et al., 2017; Liu et al., 2009). Lake

41 area in the TP has been increasing, which is the opposite of the changes in other regions of China (Ma et

42 al., 2010), Asia's plateaus (Zhang et al., 2017a), and other regions or drainage basins across the globe

43 (Donchyts et al., 2016). Furthermore, alpine lakes in the endorheic basin have a unique role as they serve

44 as nodes linking atmospheric, cryospheric, and biospheric components of the hydrological cycle. To

45 understand climate change forcing on regional hydrological cycles in the region, it is essential to monitor

46 the volume change of these alpine lakes (Song et al., 2014).

Due to the harsh environment and few in situ observations, satellite remote sensing has become an indispensable tool for studying the dynamics of alpine lakes in the TP (Song et al., 2016; Song et al., 2017; Wan et al., 2016). The advent of satellite imagery makes it possible for long-term and large-scale monitoring of alpine lakes (Lei et al., 2017; Li et al., 2019; Song et al., 2016; Yang et al., 2017a; Yao et

51 al., 2018; Zhang et al., 2017b; Zhou et al., 2015) and lake volume changes in the TP have been examined using Landsat data (Ma et al., 2010; Song et al., 2014; Zhang et al., 2017a). Table 1 summarizes recent studies on lake volume changes in the region. In the two most recent studies, Li et al. (2019) examined multiyear changes in water level and storage of 52 lakes with an area larger than $150 \mathrm{~km}^{2}$ in the TP using altimetry and optical remote sensing images during 2000-2017. Yao et al. (2018) integrated optical imagery and digital elevation models and studied the lake water storage (LWS) change of 871 lakes from 2002-2015 in the Changtang Plateau (CP) of north-western TP. However, existing studies are limited to either some large lakes, specific years (every 5 or 10 years), or only for a time span of less than 15 years.

59 According to existing research, there are about 1200 lakes with an area larger than $1 \mathrm{~km}^{2}$ in the TP (Zhang

60 et al., 2017a; Zhang et al., 2020) and earth observation satellites, such as Landsat mission, span more

61 than 30 years (Huang et al., 2017). However, existing studies have neither made full use of existing earth 
64 the hydrological system in the region.

65 Table 1: Recent lake studies and datasets in the TP.

\begin{tabular}{|c|c|c|c|}
\hline Study & $\begin{array}{l}\text { No. of } \\
\text { lakes }\end{array}$ & Temporal resolution & Timespan \\
\hline $\begin{array}{l}\text { Zhang et al. } \\
\text { (2017b) }\end{array}$ & $60-70$ & $\begin{array}{l}\text { One record in the } 1970 \text { s and annual for } \\
\qquad 1989-2015\end{array}$ & $1972-2015$ \\
\hline $\begin{array}{l}\text { Yang et al. } \\
(2017 b)\end{array}$ & 114 & 1976, 1990, 2000, 2005 and 2013 & $1976-2013$ \\
\hline $\begin{array}{l}\text { Yang et al. } \\
\text { (2017a) }\end{array}$ & 874 & Monthly & 2009-2014 \\
\hline $\begin{array}{l}\text { Yao et al. } \\
\text { (2018) }\end{array}$ & 871 & Annual & $2002-2015$ \\
\hline $\begin{array}{l}\text { Li et al. } \\
\text { (2019) }\end{array}$ & 52 & Monthly & $2000-2017$ \\
\hline This study & 976 & Annual & 1989-2019 \\
\hline
\end{tabular}

66

67 In this research, using the Google Earth Engine (GEE) geospatial analysis platform, we analyzed Landsat

68 imagery in the past 30 years $(1989$ - 2019) to obtain annual lake area time series data for 976 lakes with

69 a maximum area larger than $1 \mathrm{~km}^{2}$ in the endorheic basin of the TP (EBTP). We further derived the

70 relationship between lake area and surface elevation using digital terrain model data and estimated the

71 annual volume change for the lakes. This study provides so far the most comprehensive census on lake

72 volume change in the EBTP.

\section{$73 \quad 2$ Study area and data}

74 The endorheic basin of the TP (78.646E-99.379E, 29.829N-39.419N), which has a total area of $1.42 \mathrm{x}$

$7510^{6} \mathrm{~km}^{2}$, can be generally divided into two sub-basins: Inner and Qaidam basins (IB and QB) (Fig. 1).

76 Most lakes in the endorheic basin were expanding under climate change (Zhou et al., 2015). 976 lakes

77 with a maximum area larger than $1 \mathrm{~km}^{2}$ were identified in this study, which had a total area of 30912.03

$78 \quad \mathrm{~km}^{2}$ in 2019. 


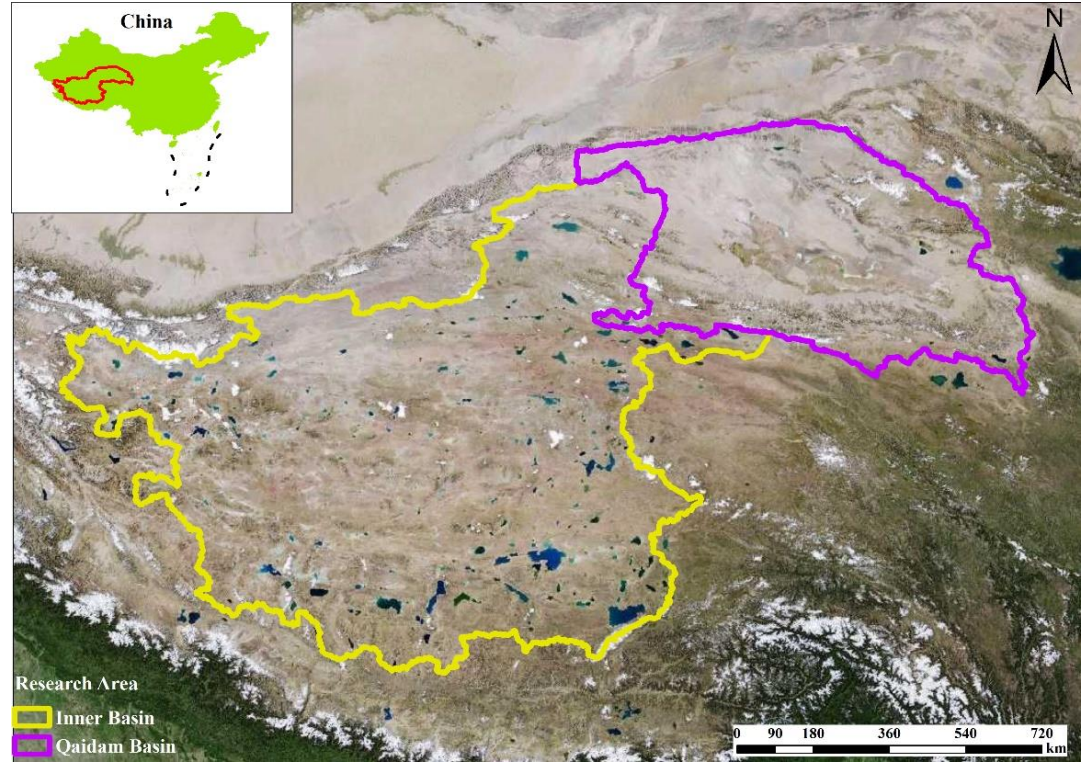

Figure 1: Study area and two sub-regions (inner basin and Qaidam basin). Background remote sensing image is from http://to.tianditu.gov.cn/img_c/wmts.

The data used in this research include Landsat imagery, Joint Research Centre Global Surface Water (JRC-GSW) data, Shuttle Radar Topography Mission (SRTM) digital elevation mode (DEM)l, Advanced Land Observing Satellite (ALOS) digital surface model (DSM), and several public lake storage data. Imagery from Landsat-5 TM (1984-2012), Landsat-7 ETM+ (1999-), and Landsat-8 OLI (2013-) was used to extract lake and calculate annual lake area. The JRC-GSW data were generated using over 3 million scenes from Landsat 5, 7, and 8 acquired between 16 March 1984 and 31 December 2019 (Pekel et al., 2016). The dataset provides monthly surface water from 1984 to 2019 and statistics on the extent and change of surface water. The dataset was used to identify individual lakes and their analysis extents in this study. SRTM DEM and ALOS DSM (digital terrain model, DTM hereafter) were used to delineate lake's approximate extents from JRC-GSW data (see Sect. 3.1) and to establish the relationship between lake area and water surface elevation (see Sect. 3.4).

For validation purpose, we compared our results with a widely used lake surface elevation/storage data from the Laboratoire d'Etudes en Géophysique et Océanographie Spatiales (LEGOS) Hydroweb (Crétaux et al., 2011) and two most recent lake volume data from Li et al. (2019) and Yao et al. (2018). For these datasets, we used the overlapping lakes in the comparison. 
98 In this research, calculating the lakes relative volume can be divided into two steps. The first step is to identify individual lakes, determine their analysis extents, and calculate annual lake area from Landsat imagery. The second step is to derive lake area-elevation relationship, estimate lake surface elevation from lake area, and calculate lake volume change. Details in the first step are shown in Fig. 2, which include three sub-steps: lake identification, analysis extent and seed determination (Sect. 3.1), water classification and segmentation (Sect. 3.2), and annual lake area calculation (Sect. 3.3). For the second step, Sect. 3.4 explains the way we construct the lake surface elevation-area relationship and Sect. 3.5 explains how to get the lake annual relative volume.

106

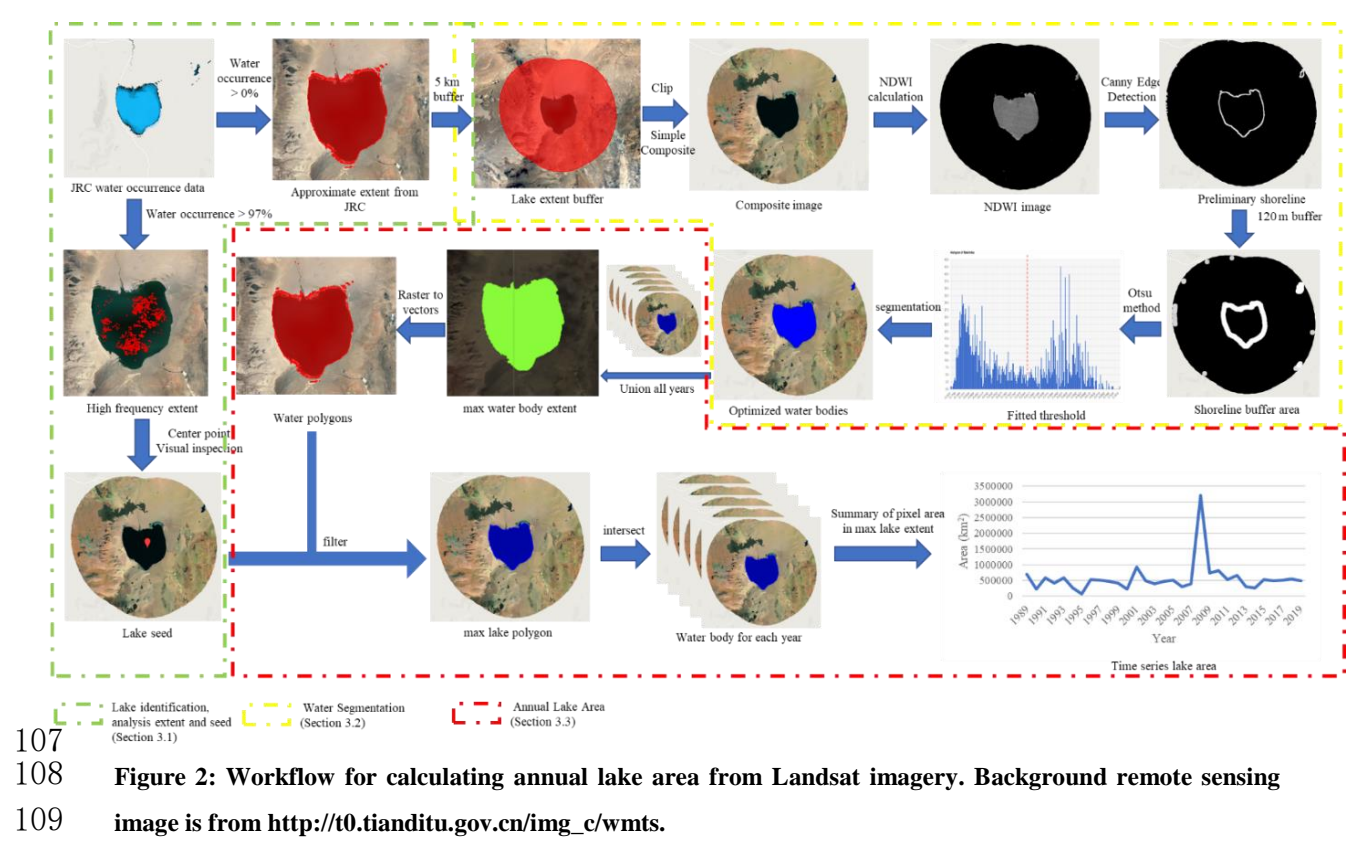

\section{$110 \quad 3.1$ Lake identification and analysis extent and seed determination}

111 Due to the vast size of the EBTP and long term of Landsat imagery, we need to limit image processing

112 to the lakes and their surrounding areas, so as to reduce computing resources and improve efficiency. For

113 this purpose, we first need to identify the lakes and determine their analysis extents. Methods introduced

114 in the following sections are all performed inside a lake's analysis extents. 
115 We used the JRC-GSW data to identify the lakes in the study area. All the pixels with a positive water

116 cover frequency on the water occurrence band of the JRC-GSW data were retained, representing the

117 maximum water extent between 1984 and 2019. From those water pixels, spatially connected pixels were

118 identified as individual waterbodies and those with an area larger than $1 \mathrm{~km}^{2}$ were kept. Some of those

119 waterbodies include both lakes and the rivers connected with them, especially for large lakes (Fig. 3).

120 The border between lakes and rivers is hard to define but we assume that the primary waterbody of a lake

121 is relatively flat and should have a slope close to zero. We used SRTM DEM to calculate the slope for

122 each waterbody pixel. Pixels with a slope greater than $0^{\circ}$ are considered rivers and removed from the

123 waterbody. In this step, several patches of waterbody pixels may occur. We visually inspected those

124 patches and only kept the patch that represents the approximate extent of the lake associated with the

125 waterbody. This approach worked effectively for water bodies larger than $50 \mathrm{~km}^{2}$ and the approximate

126 lake extents of 490 lakes were identified this way. In the process, we found there is a river linking two

127 lakes from high resolution remote sensing images (see Sect. 5.1 and Fig. 15). For these two lakes, the

128 linking river was kept and these two lakes were treat as one lake in our research. This situation happened

129 only once and these two lakes were usually treated as separate lakes in former reseach (Li et al., 2019;

130 Yao et al., 2018). The above procedure, however, tends to remove many small waterbodies entirely. So

131 for waterbodies less than $50 \mathrm{~km}^{2}$, we inspected each waterbody visually and manually drew the

132 approximate lake extents, and we identified 486 more lakes and their approximate extents. Altogether,

133 we identified a total of 976 lakes and their approximate extents in the study area. Buffers of the

134 approximate lake extents were generated and used as analysis extents for the lakes so the accuracy of the

135 approximate lake extents is not an issue. 

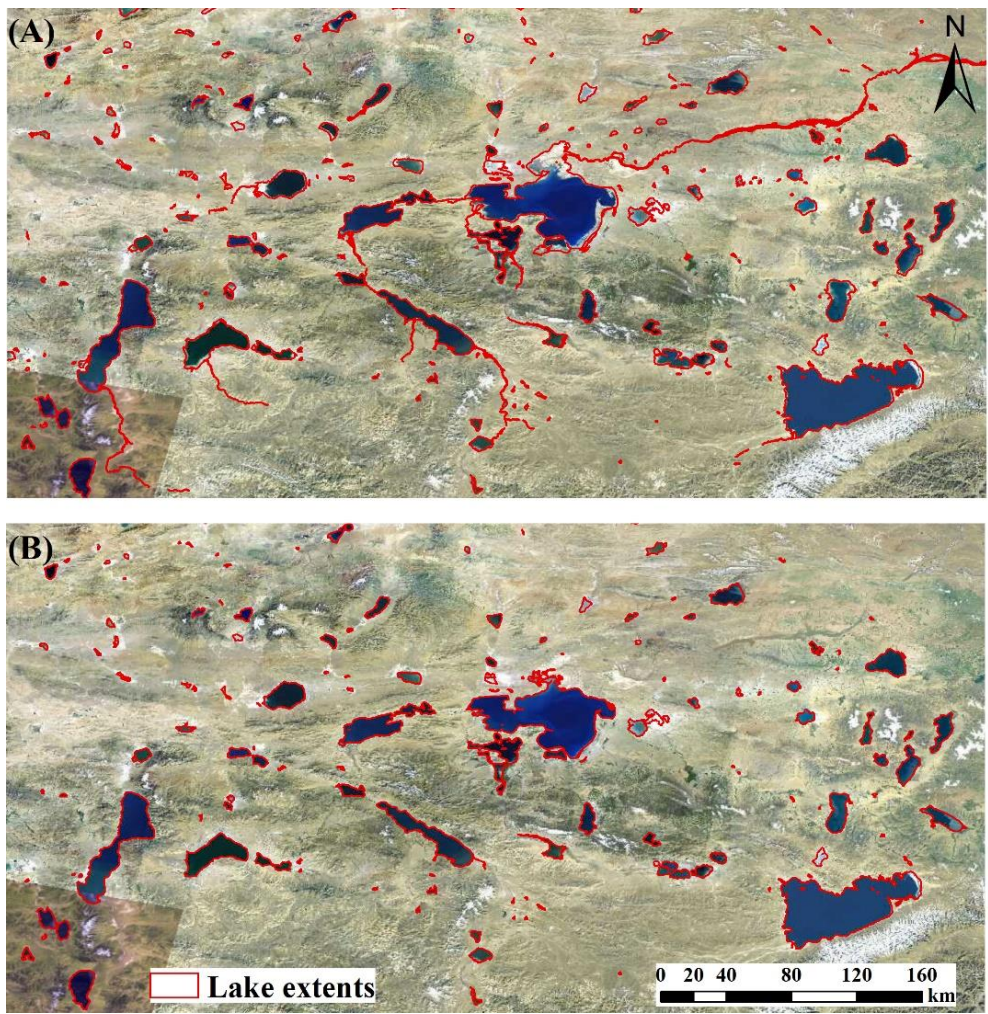
http://t0.tianditu.gov.cn/img_c/wmts.

In addition to lake approximate extents, a point is created for each lake (hereafter lake seed) to identify and distinguish the target lake from other waterbodies within its analysis extent. The centroid point of each lake's approximate extent was calculated as the initial lake seed location but these points were manually checked and edited if necessary to make sure they are inside their lake approximate extents.

\subsection{Water segmentation}

145 Although the JRC-GSW data provide global monthly surface water map, it is not designed for mapping alpine lakes specifically. As such, we developed our own method for mapping lakes in the EBTP from

147 Landsat imagery.

Based on the lake approximate extents obtained in Sect. 3.1, a $5 \mathrm{~km}$ buffer was generated around each

149 extent and all the analyses hereafter in this section are confined to this analysis extent. Since there are 
151 (Gorelick et al., 2017) was used for image processing and data analysis. We first selected Landsat images

152 between June and November in each year to exclude images with snow and ice. Landsat quality

153 assessment band (hereafter BQA band) was used to remove cloud, shadow, saturation (for Landsat 5, 7

154 and 8) and terrain occlusion (for Landsat 8 only) pixels on each image. A composite image was then

155 generated with the selected images using the SimpleComposite function in GEE. The function computes

156 a Landsat top of atmosphere (TOA) composite from a collection of raw Landsat scenes. It calculates a

157 cloud score (between 0 and 100) at each pixel for each image, selects the pixels with a cloud score less

158 than a certain threshold, and calculate a percentile pixel value for the composite image. In this research,

159 we used a cloud score threshold of 10 and a percentile value of 0 . By using this function with the

160 parameters, we removed most cloud and generated annual max-water composite images. More details on

161 the function can be found at https://developers.google.com/earth-engine/guides/landsat\#simple-

162 composite.

163 With the annual composite images, lake water pixels are classified using normalized difference water 164 index (NDWI) (Gao, 1996):

where $B_{G}, B_{N I R}$ refer to green and near infrared bands, which is band 2 and 4 for Landsat 5/7 TM/ETM+ images and bands 3 and 5 for Landsat 8 OLI images, respectively. Several other indexes have been used for lake mapping, such as modified NDWI (MNDWI) (Weekley and Li, 2019), normalized difference moisture index (NDMI) (Elsahabi et al., 2016), and water ratio index (WRI) (Barbieux et al., 2018;

170 Elsahabi et al., 2016). We chose NDWI in this study as existing research indicated that NDWI appears

171 to be more robust in detecting lake extent under various water conditions (Qiao et al., 2019; Rokni et al., 172 2014).

173 Thresholding (or segmentation) is a key step in extracting water pixels from NDWI images. Usually, 174 pixels with a NDWI value greater than 0 are considered as water. However, because of disparate 175 geographical environment and dynamic water conditions, it is impossible to use the same NDWI 176 threshold for all the lakes in all the years. In this research, we used local Otsu method (Otsu, 1979; Setiawan et al., 2017) to dynamically segment NDWI images. Specifically, a Canny edge detection algorithm (Bao et al., 2005) was first used to extract lake shorelines from NDWI images (see the yellow 

extent and, from which, we then identified the spatially connected water pixels which contains the lake's seed as the lake's maximum water extent during the study period. The maximum lake water extent is then used to identify annual lake water pixels and calculate annual lake area (see red box in Fig. 2). In this way, even if a lake has separate waterbodies in some of the years, all the waterbodies are counted as parts of the same lake.

190 The Landsat imagery has several series, including Landsat-5 TM (1984-2012), Landsat-7 ETM+ (1999-), and Landsat-8(Cristóbal et al., 2009). When imagery from multiple sensors (Landsat $5 \& 7$ and $7 \& 8$ ) are available, lake area was calculated separately from each sensor and then combined. If the relative difference between the sensors is within $2 \%$, the average area is used for the year. Otherwise, annual Landsat composite images and lake boundaries were manually examined to decide which area is more accurate. In addition, annual lake area was manually checked if there is a significant change from previous and following years. If the annual composite image is contaminated and unreliable, lake area for the year was linearly interpolated using prior and later year's lake area. Through those steps, we obtained the annual maximum lake area for each lake from Landsat imagery.

\subsection{Lake surface elevation}


205 Without lake bathymetry data, we can only estimate lake surface elevation based on the elevation-area

206 relationship derived from DTM collected after 2000 assuming that the slope below lake surface is similar 207 to that above lake surface in 2000 (Yang et al., 2017b). Some commonly used methods include linear equation (Yang et al., 2017b), second order parabolic equation (Li et al., 2019) and monotonic cubic spline fitting (Yao et al., 2018). These methods have their own advantages and disadvantages. While the linear interpolation is the simplest, more complicated methods such as the cubic spline interpolation, which constructs polynomial functions, can fit data more smoothly (Gray et al., 2018). Linear regression is usually suitable for elevation-area relationship with a fixed slope. And second order parabolic equation is suitable for simulating the relationship with small changes in slope. The monotonic cubic spline fitting can model the elevation-area relationship with large slope changes (Gray et al., 2018).

215 Although existing research indicates that monotonic cubic interpolation (MCI) has the best performance in fitting elevation-area relationship (Yao et al., 2018), we found that MCI may overfit (see Sect. 5.2). In this research, a combination of linear regression (LR), second order polynomial regression (SOPR), and MCI methods was used to derive the elevation-area relationship which was then used to estimate surface elevation based on lake area. The elevation-area pairs, where the elevation starts at from the lowest elevation, stops at the highest elevation and increases at an interval of $1 \mathrm{~m}$ within each lake analysis extent, were obtained from SRTM and ALOS separately. At each elevation, pixels with an elevation less than the current elevation are kept and connected components are identified. The maximum lake water extent (see 3.4) is then used to select the components belonging to the lake. The sum of all the components' area is calculated as the area for the current elevation. The minimum (MinA) and maximum (MaxA) annual lake area from Landsat are then used to select the elevation-area pairs whose area is in the range of [MinA/1.5, MaxA*1.5] from both SRTM and ALOS, and the list with more elevation-area pairs is kept. If the two lists have the same length, the SRTM list is kept. The choice of the data fitting methods depends on the number of elevation-area pairs in the range of [MinA/1.5, MaxA*1.5], which is discussed below and summarized in Table 2:

230 (1) If the number of data pairs is zero or one, we generated a new list of elevation-area pairs from the 231 selected DTM with eight pairs whose area starts with MaxA*1.5. The LR method was then used to derive the elevation-area relationship (labelled LRN); 
233 (2) If the number of data pairs is two, we directly used LR to derive the elevation-area relationship

234 (labelled LRC);

235 (3) If the number of data pairs is equal to or greater than five and lake area range from the selected DTM

236 fully covers the area range ([MinA, MaxA]) from Landsat imagery, the MCI method was used;

237 (4) In other cases, the SOPR method was used. If the symmetry axis of the SOPR model falls into [MinA,

238 MaxA], the elevation-area relationship will be non-monotonic (see Sect. 5.2). To avoid this, the symmetry axis was calculated, and if the symmetry axis fell into [MinA, MaxA], LR method was used instead (labeled LRS).

Table 2: Selection of data fitting methods for deriving elevation- area relationship for each lake.

\begin{tabular}{ccc}
\hline Conditions & Method & Abbreviation \\
\hline The number of data pairs is 0 or 1 & Generate 8 new data pairs and then & LRN \\
Number of data pairs = two & use LR & LRC \\
$\begin{array}{c}\text { Number of data pairs > five and MinA is } \\
\text { larger than the minimum area from DTM }\end{array}$ & LR & MCI \\
None of the above & $\begin{array}{l}\text { SOPR but use LR when the symmetry } \\
\text { axis of SOPR falls into [MinA, MaxA] }\end{array}$ & SOPR / LRS \\
\hline
\end{tabular}

\subsection{Lake volume}

243 While it is impossible to obtain lake water volume without bathymetry data (Crétaux et al., 2016), we

244 can calculate relative lake volume (RLV) between two dates with the lake area and elevation at those

245 dates. RLV from time $\mathrm{t} 1$ to time $\mathrm{t} 2$ can be calculated by the integral of an elevation-area relationship 246 function:

$247 \quad \mathrm{RLV}_{t 1-t 2}=\int_{E_{t 1}}^{E_{t 2}} A d E=\int_{E_{t 1}}^{E_{t 2}} f(\mathrm{E}) d E$

$248 f(\mathrm{E})=A=\mathrm{a}+\mathrm{bE}+\mathrm{cE}^{2}$ or $d+e E$

249 where $\mathrm{E}$ denotes lake surface elevation, and $\mathrm{A}$ is the lake area at the elevation. $\mathrm{f}(\mathrm{E})$ is the fitted elevation-

250 area function using the LR or SOPR methods, and a, b, c, d, and e are the coefficients of the SOPR and

$251 \quad$ LR models.

252 Since the MCI function is not integrable analytically, we cut the lake volume between two dates into 253 frustums with $1 \mathrm{~m}$ intervals in elevation (Fig. 4). With an elevation list $\left[E_{t 1}, E_{t 1}+1, E_{t 1}+2, \ldots, E_{t 2}-\right.$ 


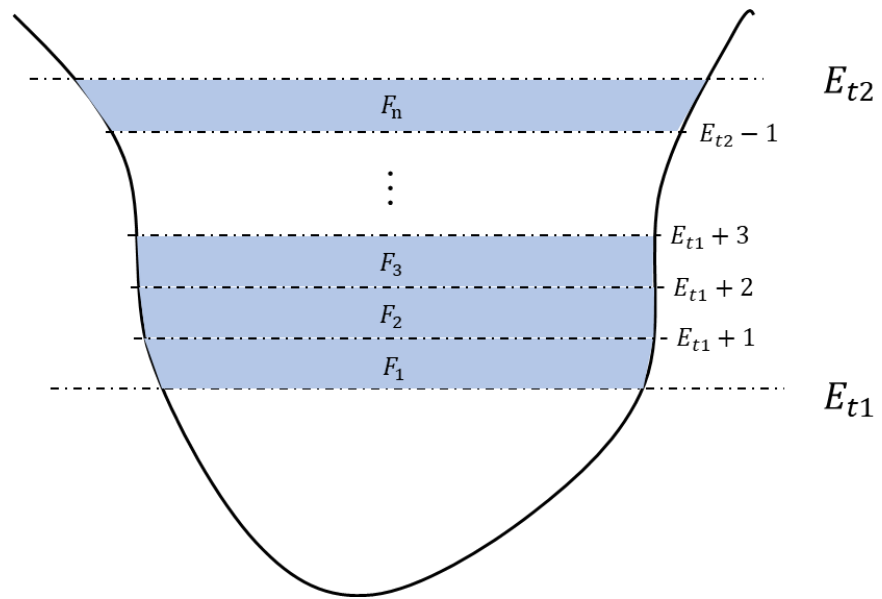

Figure 4: Schematic diagram showing how relative lake volume can be calculated using a series of frustums.

\section{Accuracy assessment}

Hydroweb (Crétaux et al., 2011) as well as several most recent lake volume data in the TP from Li et al. (2019) (referred to as Li's data hereafter) and (Yao et al., 2018) (referred to as Yao's data hereafter). as:

$272 \quad$ SMAPE $=\frac{1}{n} \sum_{i=1}^{n} \frac{2 *\left|x_{i}-y_{i}\right|}{\left|x_{i}\right|+\left|y_{i}\right|}$ 
273 where $\mathrm{n}$ is the sample size. $x_{i}$ and $y_{i}$ are $i$ th data value in our results and existing datasets, respectively.

274 The range of SMAPE is $[0,2]$ and the smaller the sMAPE, the smaller the relative error. sMAPE is a

275 scale-independent accuracy index based on percentage errors (Chen et al., 2017). Compared with

276 commonly used Root Mean Square Error (RMSE), sMAPE can be used to compare lakes with different

277 magnitude of RLV. In addition, sMAPE allows 0 in the data, which is very common in RLV. In contrast,

278 mean relative error (MRE) has issues when data values are 0. Because those reasons we used sMAPE

279 here.

280 Table 3 shows the PCC and sMAPE when comparing our results with Hydroweb (21 lakes) and Li's data

281 (40 lakes) for overlapping lakes. All the PCCs are significant with p-values less than 0.01. Compared 282 with Hydroweb data, 13 lakes (61.9\%) have a PCC larger than 0.8 and a sMAPE less than 1. Compared 283 with Li's data, 26 lakes (65\%) have a PCC larger than 0.8 and a sMAPE less than 1 . Those results suggest

284 that our results match generally well with both Hydroweb and Li's lake data.

Table 3: Comparison between our results and Hydroweb and Li's data. The lowest PCC and highest SMAPE in each column were highlighted in italic and bold font (Lake names are from Hydroweb dataset).

\begin{tabular}{lllll}
\hline Lake Name & & Hydroweb & \multicolumn{2}{c}{ Li's Data } \\
\hline Tangra-Yumco & 0.801 & sMAPE & PCC & sMAPE \\
Xuelian-Hu & 0.819 & 1.061 & 0.738 & 0.245 \\
Orba-Co & 0.693 & 0.576 & $/$ & $/$ \\
Dung-Co & $/$ & 1.195 & $/$ & $/$ \\
Memar-Co & $/$ & $/$ & 0.889 & 0.892 \\
Pung-co & 0.970 & $/$ & 0.954 & 0.508 \\
Yibug-Caka & $/$ & $/$ & 0.983 & 0.407 \\
Kyebxang-Co & $/$ & $/$ & 0.956 & 0.694 \\
Xuru-Co & $/$ & $/$ & 0.982 & 1.375 \\
Salt-Lake & $/$ & $/$ & 0.863 & 1.080 \\
Rola-Co & $/$ & $/$ & 0.990 & 0.381 \\
Salt-Water-Lake & $/$ & 0.422 & 0.995 & 0.501 \\
Zige-Tangcuo & 0.996 & $/$ & 0.742 & 1.540 \\
Bamco & $/$ & $/$ & 0.964 & 0.693 \\
Gozha-Co & $/$ & $/$ & 0.993 & 0.134 \\
Donggei-Cuona-Lake & $/$ & / & $\mathbf{- 0 . 1 1 8}$ & $\mathbf{1 . 5 5 1}$ \\
Zhuonai-Lake & $/$ & 0.684 & 0.945 & 0.947 \\
Aksayqin & 0.901 & 13 & 0.954 & 0.900 \\
\hline & & & & 1.129 \\
\hline
\end{tabular}


https://doi.org/10.5194/essd-2021-331

Preprint. Discussion started: 12 November 2021

(c) Author(s) 2021. CC BY 4.0 License.

\begin{tabular}{lllll}
\hline Co-Ngoin1 & $/$ & $/$ & 0.537 & 1.048 \\
Lixiodain-Co & 0.985 & 0.730 & 0.970 & 1.011 \\
Margai-Caka & $/$ & $/$ & 0.966 & 0.274 \\
Dagze-Co & 0.979 & 0.323 & 0.985 & 0.267 \\
Kusai-Lake & $/$ & $/$ & 0.991 & 1.286 \\
Jingyu & 0.886 & 1.562 & 0.941 & 0.534 \\
Hoh-Xil-Lake & $/$ & $/$ & 0.975 & 0.877 \\
Lumajangdong-Co & 0.978 & 1.048 & 0.978 & 1.259 \\
Dogaicoring-Qangco & 0.954 & 0.403 & 0.901 & 0.789 \\
Urru-Co & 0.790 & 1.009 & 0.384 & 1.257 \\
Goren-Co & $/$ & $/$ & 0.690 & 1.326 \\
Taro-Co & 0.384 & $\mathbf{1 . 7 0 8}$ & 0.813 & 0.786 \\
Ngangze-Co & 0.911 & 0.299 & 0.933 & 0.199 \\
Dogia-Coring & 0.983 & 0.152 & 0.975 & 0.283 \\
Xijir-Ulan-Lake & $/$ & $/$ & 0.983 & 0.661 \\
Ngangla-Ringco & $-\mathbf{0 . 1 4 0}$ & 1.263 & 0.811 & 1.140 \\
Aqqikkol-Lake & $/$ & $/$ & 0.991 & 0.560 \\
Wulanwula-Lake & 0.980 & 0.307 & 0.975 & 0.329 \\
Zhari-Namco & 0.958 & 0.496 & 0.903 & 0.590 \\
Ayakkum-Lake & 0.966 & 0.968 & 0.981 & 0.981 \\
Tu-Co & $/$ & $/$ & 0.963 & 0.340 \\
Chibzhang-Co & $/$ & 0.457 & 0.988 & 0.666 \\
Nam-Co & 0.935 & 0.411 & 0.918 & 0.273 \\
Selin-Co & 0.994 & & 0.984 & 0.231 \\
\hline & & $/$ & & \\
\hline
\end{tabular}

289 There are discrepancies among the datasets. For example, lake Ngangla-Ringco has a PCC of -0.140 and

290 sMAPE of 1.263 when compared with Hydroweb data but a PCC of 0.811 and sMAPE of 1.263 when

291 compared with Li's data. Three lakes (Ngangla-Ringco, Gozha-Co, Taro-Co), which have the largest

292 difference from our dataset and are highlighted in Table 5, were further examined. For Ngangla-Ringco,

293 Fig. 5 shows the differences in lake area and surface elevation between our results and the two existing

294 datasets. From 2016 to 2019, while our and Li’s lake surface elevation both show a significant increase,

295 Hydroweb elevation has a slight decrease. And from 2002 to 2019 , our lake area is around $500 \mathrm{~km}^{2}$ but

296 Hydroweb lake area is about $240 \mathrm{~km}^{2}$, only about half of our lake surface area. 


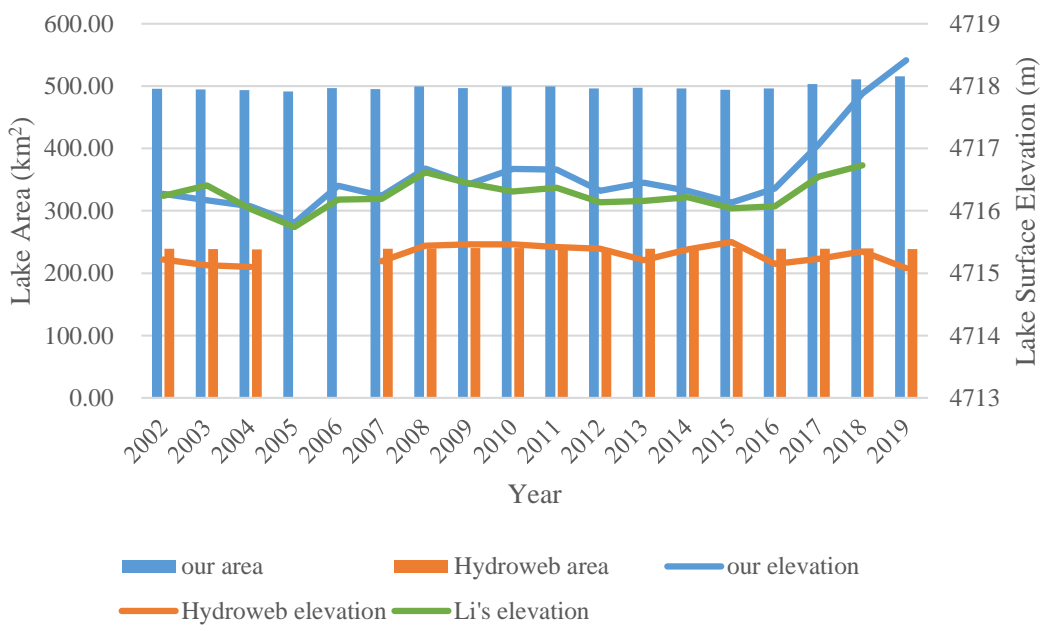

Figure 5: Comparison of lake area and lake surface elevation between our results and two existing data (Hydroweb and Li's data) for lake Ngangla-Ringco from 2002 to 2019. The y-axis on the left, representing lake area, is for the vertical bars. The y-axis on the right, representing lake surface elevation, is for the lines.

The boundaries of lake Ngangla-Ringco in 2008 (before significant increase) and 2018 (after significant increase) are shown in Fig. 6 with SRTM DEM added to illustrate lake boundary elevation in these two years. The mean lake boundary elevation is 4716.68 and 4717.88 meters in 2008 and 2018 respectively and Fig. 6C-E show a distinct increase in surface elevation between the years. Our lake boundaries (Fig. 6A-B) fit well visually with the lake on the composite images, indicating our lake areas are more credible than Hydroweb data for the lake. Although our annual composite images tend to extract the maximum lake extent within a year, it is unlikely the lake area is twice as large as that in Hydroweb. 

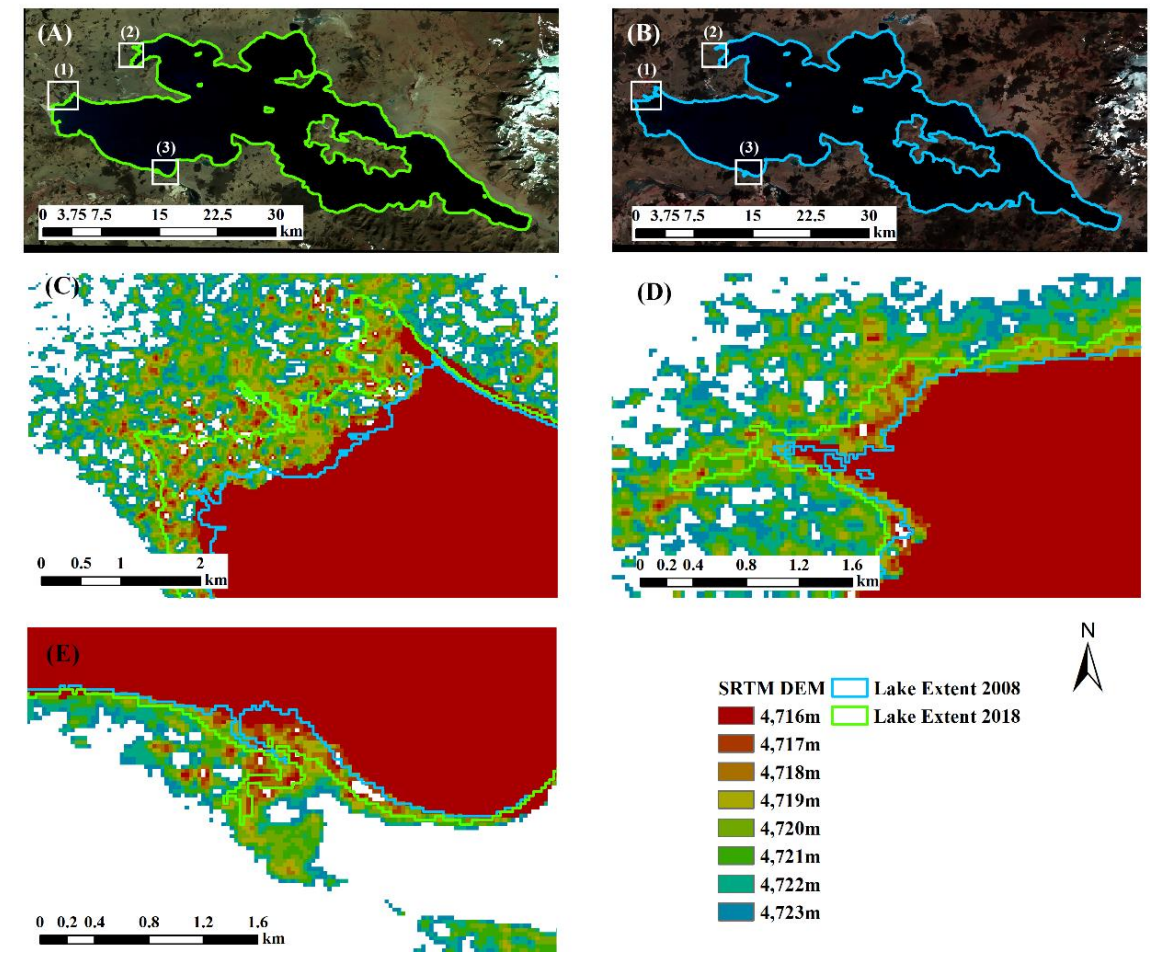

$\stackrel{N}{N}$

Figure 6: Lake extents in 2018 (A) and 2008 (B) and in three close-up areas (C), (D) and (E) (corresponding to boxes (1), (2), (3) in (A) and (B), respectively) from our results for lake Ngangla-Ringco. Images in (A) and (B) are composite image (R: Near-infrared band, G: Red band, B: Green band ) from Landsat 5 and Landsat 8 respectively. DEM shown in $(C)-(E)$ are SRTM DEM.

315 Lake Gozha-Co showed distinct trends in lake surface elevation and volume between our results and Li's

316 data (Fig. 7). In Li's data, lake surface elevation rose from 2001 to 2009 with the highest elevation of

$3175084.43 \mathrm{~m}$ in 2009 , and then started a decrease trend. In our results, lake surface elevation fluctuated but

318 generally had been decreasing from 2001 to 2018. While our results have an elevation range between

3195079 and $5081 \mathrm{~m}$, the elevation range of Li's data is between 5083 and $5085 \mathrm{~m}$, which leads to extremely

320 larger lake volume compared with our data. 


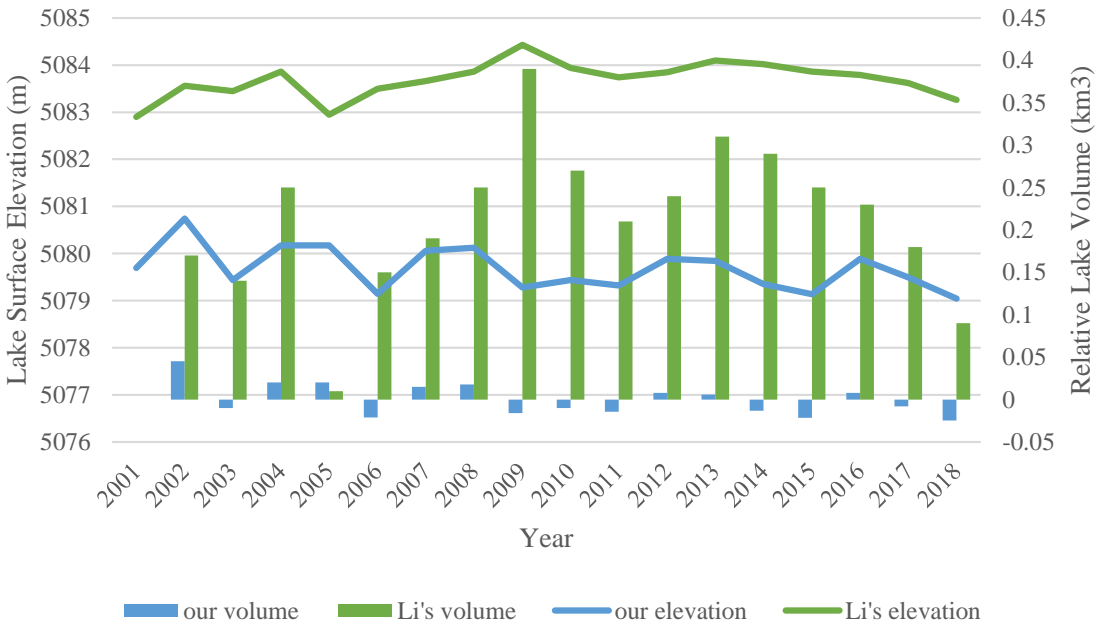

322 Figure 7: Comparison of relative lake volume and lake surface elevation between our results and two existing data (Hydroweb and Li's data) for lake Gozha-Co from 2001 to 2018. The y-axis on the left, representing ake surface elevation, is for the lines. The y-axis on the right, representing raletive lake volume, is for the vertical bars.

For further assessment, extracted extents (Fig. 8A-C) for lake Gozha-Co in 2002, 2009, and 2018 and meters in 2002, 2009 and 2018 respectively and Fig. 8D-E show no distinct change in surface elevation, confirming our surface elevation is more reliable. Fig. 8 also shows that the highest lake surface elevation occurred in 2002 rather than 2009, and the lake surface elevation in 2009 and 2018 did not differ much. 

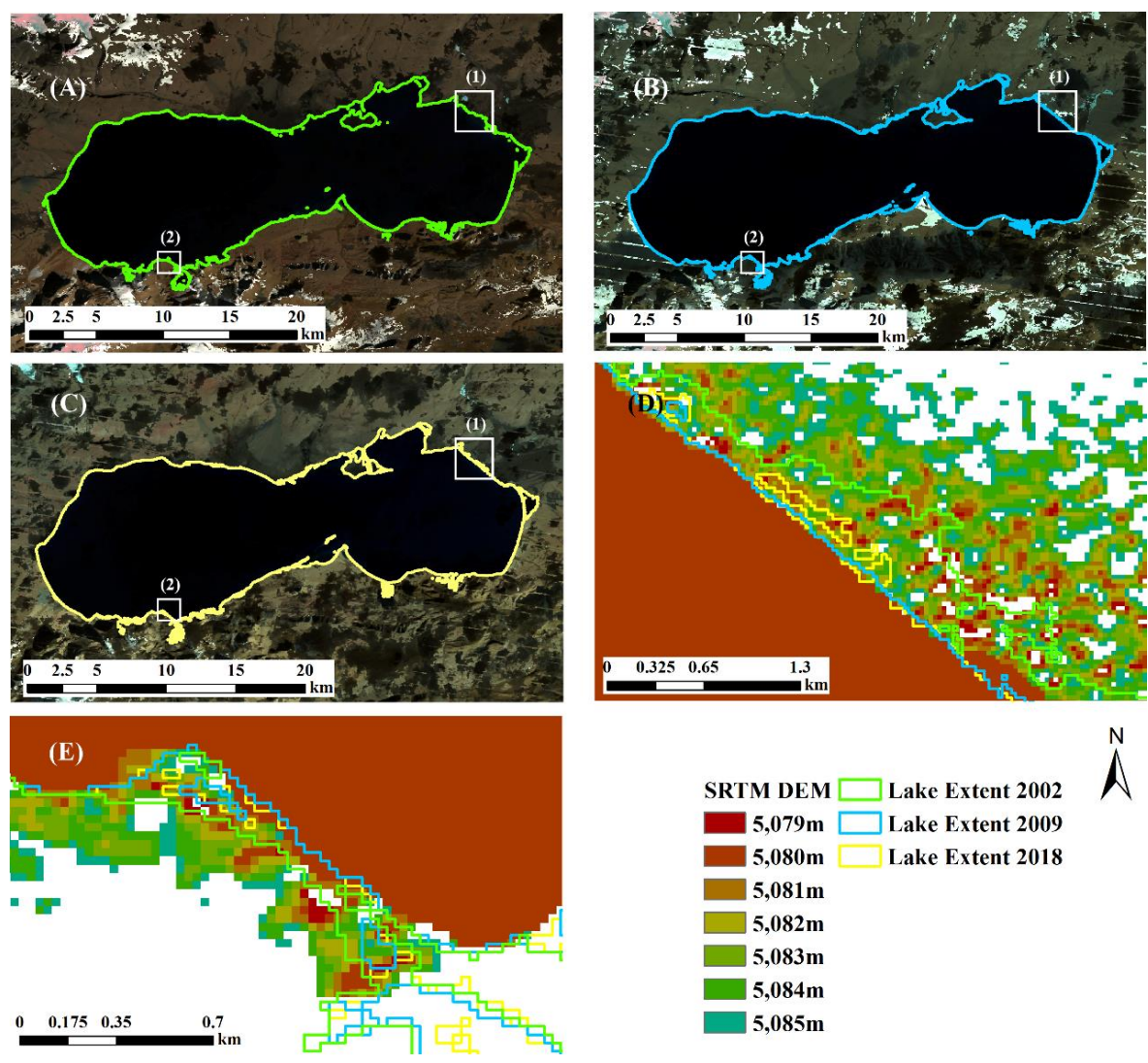

Figure 8: Lake extents in 2002 (A), 2009 (B), and 2018 (C) and two close-up areas (D), and (E) (corresponding to boxes (1) and (2) in image (A), (B) and (C), respectively) from our results for lake Gozha-Co. DEM shown in (D) and (E) are SRTM DEM . Composite images in (A)-(C) (R: Near-infrared band, G: Red band, B:Green band) are from Landsat 7 .

340 Figure 9 shows the differences in lake area and surface elevation among the datasets for lake Taro-Co.

341 Our results and the two existing datasets generally have a similar increase trend in surface elevation in

342 2004-2008. In our results, surface elevation had been increasing from 2015 to 2018 but Hydroweb

343 elevation experienced a decrease from 2015 to 2016 and Li's elevation had also been decreasing from

3442017 to 2018. In addition, both our area and elevation fluctuated more than the other two datasets. 


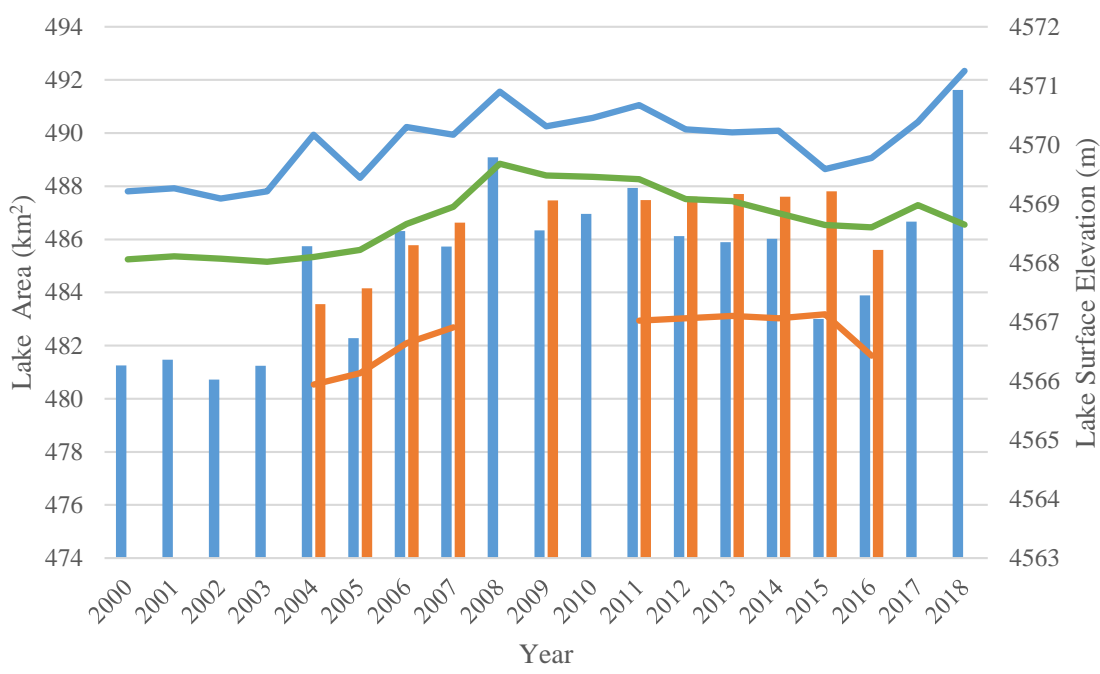

our area Hydroweb area

Hydroweb elevation -Li's elevation

Figure 9: Comaprison of lake area and lake surface elevation between our results and two existing data (Hydroweb and Li's data) for lake Taro-Co from 2000 to 2018. The y-axis on the left, representing lake area, is for the vertical bars. The $y$-axis on the right, representing lake surface elevation, is for the lines.

For further assessment, the extracted extents (Fig. 10A-C) for lake Taro-Co in 2015, 2016, and 2018 and SRTM DEM were shown in Fig. 10. Our lake boundaries visually fit well with lake extents on the composite images and the mean elevation of the lake boundaries is $4569.59 \mathrm{~m}, 4569.77 \mathrm{~m}$, and 4571.25 m, respectively. A significant increase in lake surface elevation in 2018 can be clearly observed in Fig. 10D-E. 


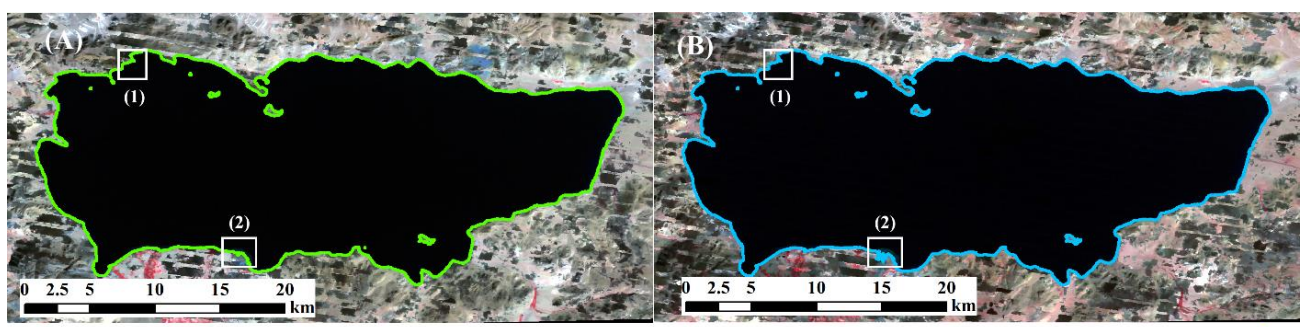

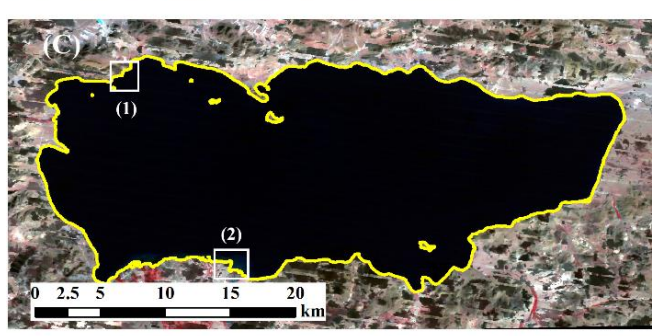

(E)

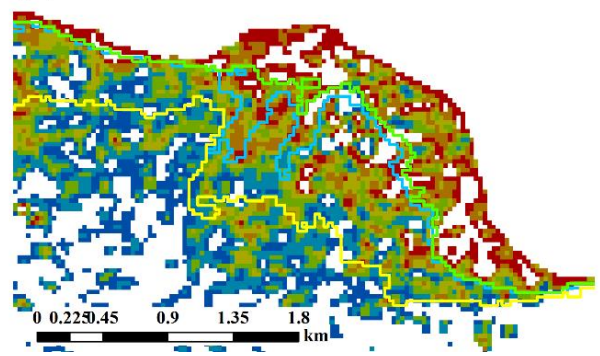

(D)

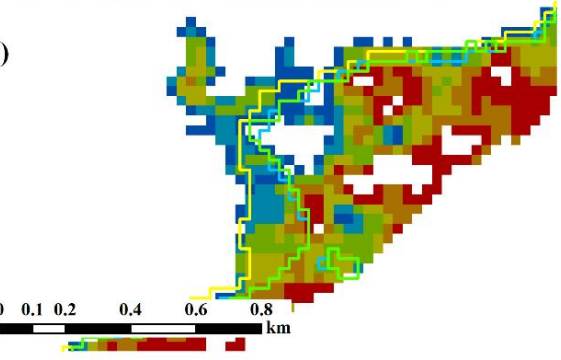

$\stackrel{N}{N}$

Figure 10: Lake extents from our analysis for lake Taro-Co in 2015 (A), 2016 (B), and 2018 (C) and two close-

358 up areas (D), and (E) (corresponding to boxes (1) and (2) in image (A), (B) and (C), respectively). DEM shown

359 in (D) and (E) are SRTM DEM . Composite images in (A)-(C) (R: Near-infrared band, G: Red band, B:Green

360 band) are from Landsat 7.

361

362 Yao et al. (2018) also published a lake storage data in the IB. Their datasets include the annual RLV for

363871 lakes with an area larger than $1 \mathrm{~km}^{2}$ from 2009 to 2015, and the annual RLV for 126 lakes with an

364 area larger than $50 \mathrm{~km}^{2}$ from 2002 to 2015. We found 816 overlapping lakes from 2009 to 2015 and all

365 the large lakes (126) in our dataset. The main reason that our dataset has less lakes in the IB is that

366 connected waterbodies were counted as separate lakes in Yao's data (as shown in Fig. 11). 

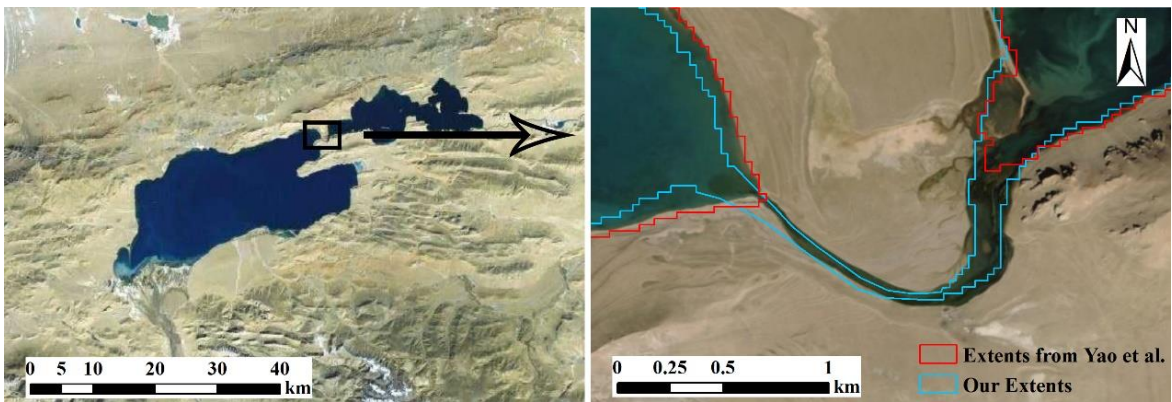

Figure 11: An example that connected waterbodies were counted as separate lakes in Yao's data. Remote sensing image is from http://t0.tianditu.gov.cn/img_c/wmts. Background remote sensing image is from http://t0.tianditu.gov.cn/img_c/wmts.

The PCC and sMAPE for the overlapping lakes (816) are shown in Table 4. For lakes larger than $1 \mathrm{~km}^{2}$, when the p-value is greater than 0.05 , the PCCs of all lakes are less than 0.8 , and $84.01 \%$ of lakes have sMAPE greater than 1 . This means that for these 371 lakes, there is a big difference between our results and Yao's data. There are 389 lakes $(47.67 \%$ ) have a PCC greater than 0.8 and a p-value less than 0.05 , and $71.91 \%$ of lakes have a sMAPE less than 1 . This means that for these 445 lakes, our results have high consistency with Yao's. For lakes with an area greater than $50 \mathrm{~km}^{2}, 109$ out of $126(86.51 \%)$ lakes have p-value less than 0.05 . For lakes with p-value less than $0.05,86$ out of 109 (78.90\%) lakes have PCC larger than 0.8 and $73.40 \%$ lakes have sMAPE less than 1. Overall, most of our lake data match well with Yao's data. Because Yao et al. (2018) did not provide lake area and surface elevation data, it is difficult for us to further examine the discrepancy.

Table 4: Data comparison statistics between our results and Yao's data.

\begin{tabular}{|c|c|c|c|c|c|c|c|}
\hline Dataset & p-value & Total & PCC $<0.6$ & $0.6 \geq$ PCC $<0.8$ & $P C C \geq 0.8$ & SMAPE $<1$ & SMAPE $\geq 1$ \\
\hline \multirow{2}{*}{ Lake area $>1 \mathrm{~km}^{2}$} & $>0.05$ & 371 & 251 & 120 & 0 & 84 & 287 \\
\hline & $\leqslant 0.05$ & 445 & 5 & 51 & 389 & 320 & 125 \\
\hline \multirow{2}{*}{ Lake area $>50 \mathrm{~km}^{2}$} & $>0.05$ & 17 & 17 & 0 & 0 & 2 & 15 \\
\hline & $\leqslant 0.05$ & 109 & 3 & 20 & 86 & 80 & 29 \\
\hline
\end{tabular}


386 In summary, our results generally show a high consistency with the existing datasets, though large

387 discrepancy does exist for some of the lakes. Close examination on a few extreme lakes indicated that

388 our results are more reliable and more in line with Landsat imagery and SRTM DEM.

\section{$389 \quad 5$ Results}

390 We identified a total of 976 lakes in the EBTP, and their maximum extents during the study period are

391 shown in Fig. 12. 930 of those lakes (95.29\%) are located in the Inner Basin, and only 46 (4.71\%) are in

392 the Qaidam Basin. Large lakes are primarily located in the southern and eastern periphery of the inner

393 basin

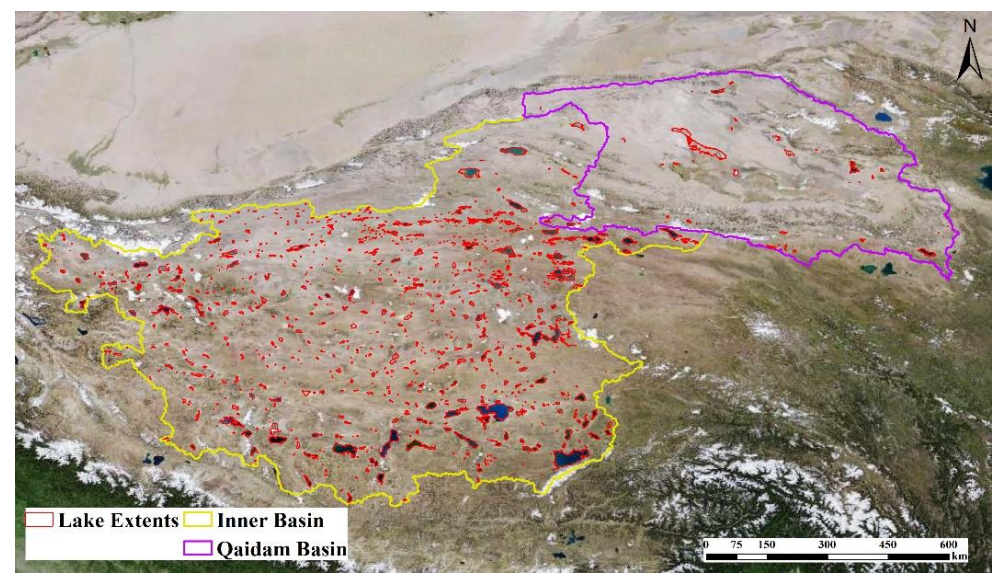

Figure 12: A total of 976 lakes larger than $1 \mathrm{~km}^{2}$ identified in the EBTP. Remote sensing image is from http://t0.tianditu.gov.cn/img_c/wmts.

\section{$397 \quad 5.1$ Lake water volume change}

398 Total lake volume in the study area exhibited a net increase of $193.45 \mathrm{~km}^{3}$ from 1989 to 2019 with an

399 increase rate of $6.45 \mathrm{~km}^{3}$ year $^{-1}$. Although lake volume was generally increasing in the past 30 years, it varied significantly from year to year. Figure 13 shows annual total loss, gain, and net change of lake volume from 1989 to 2019 . The lakes experienced water gain in 23 years and loss only in 7 years in the

40230 years of study period. From 1998 to 2013, the lakes experienced the longest continuous water gain of

40316 years. The largest water gain of $25.19 \mathrm{~km}^{3}$ appeared in 2000 , and the largest water loss of $-18.15 \mathrm{~km}^{3}$ occurred in 1994. 


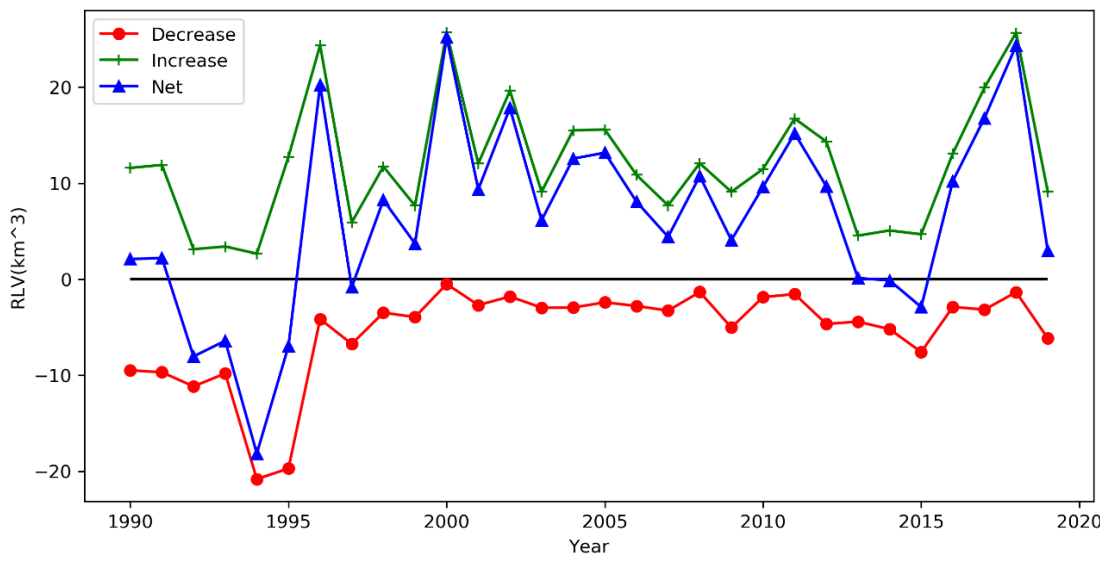

Figure 13: The gain, loss and net lake water volume in the EBTP from 1989 to 2019.

Figure 14 shows the trend of annual RLV in the entire study period and in 7-year periods (1989-1995, 1995-2001, 2001-2007, 2007-2013, 2013-2019) at each lake. Positive trend slope represents an overall increase in lake volume and vice versa. Similar to some previous studies (Yao et al., 2018; Zhang et al., 2017b), 909 lakes (93.14\%) had been expanding in the study period with the exception of 67 lakes (6.86\%). 16 lakes gained more than $0.1 \mathrm{~km}^{3}$ of water per year, and these lakes are mainly located in the east side of the IB (Fig. 14A).

RLV trend varied in the 7-year time periods. From 1989 to 1995, only 418 lakes (42.83\%) experienced volume expansion, and in fact, a noticeable lake shrinkage is observed from 1989 to 1995 (Fig. 14B) where most lakes have a decreasing trend and lakes with large RLV decrease $\left(>0.1 \mathrm{~km}^{3}\right.$ per year) are mostly located on the east or west side of IB. From 1995 to 2001 (Fig. 14C), 816 lakes (83.61\%) had been expending. While most lakes in the QB were still decreasing, most lakes in the IB had increase trend with large RLV increase $\left(>0.1 \mathrm{~km}^{3}\right.$ per year) mostly located at the north, east and south periphery of the IB. From 2001 to 2007 (Fig. 14D), though the changing trend is similar to 1995-2001, the increase rate got smaller as there are more yellow lakes than light green lakes in Fig. 14D, indicating more lakes have negative changing rate $\left(-0.05-0 \mathrm{~km}^{3} / \mathrm{y}\right)$ in 2001-2007. The increasing trend in 2007-2013 (Fig. 14E) is very similar to the previous period but with a lower rate as there are less large increase lakes (dark blue lakes) and a couple of large decrease lakes (red lakes). From 2013 to 2019 (Fig. 14F), strong increasing trend occurred again with more blue lakes in both IB and QB. 


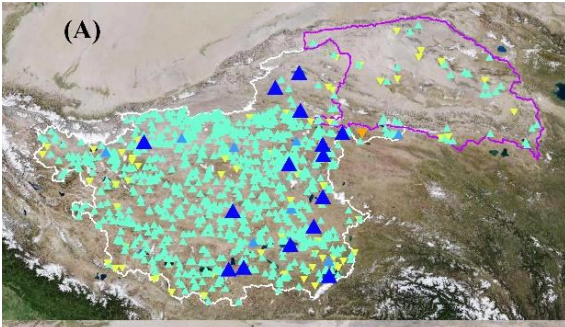

(C)

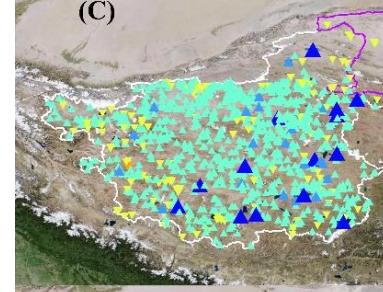

(E)

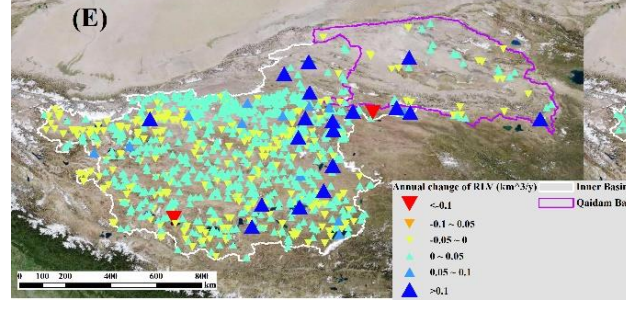

(F)

(B)

(B)

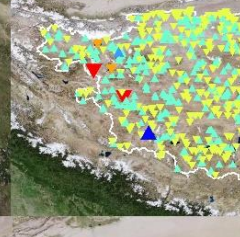

(D)
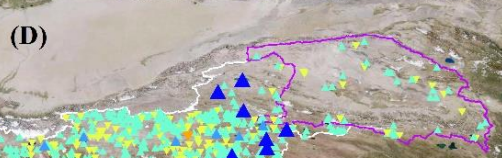

N.
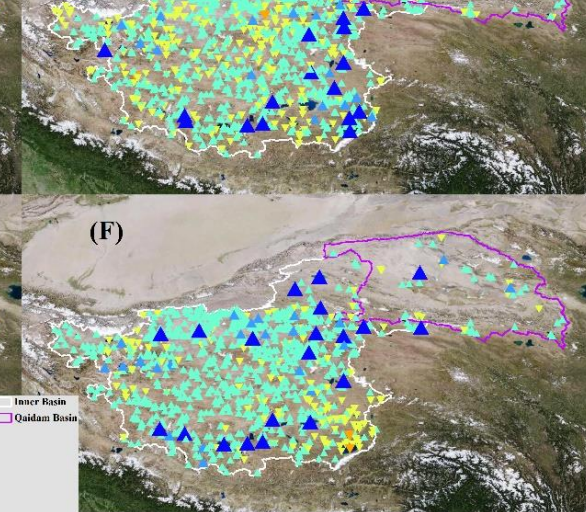

Figure 14: Trend of annual RLV during the periods of (A) 1989-2019, (B) 1989-1995, (C) 1995-2001, (D) 20012007, (E) 2007-2013, and (F) 2013-2019. Background remote sensing image is from http://t0.tianditu.gov.cn/img_c/wmts.

Trend analysis was performed for the EBTP, its sub-regions (IB, QB) and different time periods. The slope and coefficient of determination $\left(\mathrm{R}^{2}\right)$ are shown in Table 5. It suggests that there was a significant increasing trend both in the TP and IB in the recent 30 years. While the trend slope is positive in the QB (0.0700), it is much smaller than that of EBTP (7.28) and IB (7.45). $\mathrm{R}^{2}$ in the QB is 0.242 and it's significant at 0.01 confidence level indicating a weak increasing trend. Trends in the IB and EBTB are similar in the 7-year periods but this is not the case in the QB. This is mainly due to that most of the lakes are located in the IB. Trend slopes in Table 5 correspond well to Fig. 14 which indicate that the entire EBTB experienced a lake volume decrease (slope $=-6.47, \mathrm{R}^{2}=0.800$ ) in 1989-1995. In 1995-2001, IB's

440 lake volume increased (slope $=10.23, \mathrm{R}^{2}=0.925$ ) while $\mathrm{QB}$ 's lake volume decreased (slope $=-0.153$, $441 \mathrm{R}^{2}=0.708$ ). From 2001 to 2019 , although the overall volume of lake water has been increasing, the slope in 2007-2013 (8.93) was less than that in 2001-2007 (10.43) and 2013-2019 (9.92). 
https://doi.org/10.5194/essd-2021-331

Preprint. Discussion started: 12 November 2021

(c) Author(s) 2021. CC BY 4.0 License.

444 Table 5: Trend of total RLV in EBTP and its sub-region IB and QB in different time periods (* indicates 445 significant at a confidence level of $\mathbf{0 . 0 1}$ ).

\begin{tabular}{ccccc}
\hline Time Period & Index & EBTP & IB & QB \\
\hline \multirow{2}{*}{$1989-2019$} & Slope $\left(\mathrm{km}^{3} \cdot \mathrm{year}^{-1}\right)$ & 7.28 & 7.45 & 0.0700 \\
& $\mathrm{R}^{2}$ & $0.921^{*}$ & $0.923^{*}$ & 0.242 \\
\multirow{2}{*}{$1989-1995$} & Slope $\left(\mathrm{km}^{3} \cdot \mathrm{year}^{-1}\right)$ & -6.47 & -6.29 & -0.174 \\
& $\mathrm{R}^{2}$ & 0.800 & 0.797 & 0.631 \\
\multirow{2}{*}{$1995-2001$} & Slope $\left(\mathrm{km}^{3} \cdot \mathrm{year}^{-1}\right)$ & 10.08 & 10.23 & -0.153 \\
& $\mathrm{R}^{2}$ & 0.921 & 0.925 & $0.708^{*}$ \\
$2001-2007$ & Slope $\left(\mathrm{km}^{3} \cdot \mathrm{year}^{-1}\right)$ & 10.43 & 10.28 & 0.156 \\
& $\mathrm{R}^{2}$ & $0.978^{*}$ & $0.979 *$ & $0.439^{*}$ \\
$2007-2013$ & Slope $\left(\mathrm{km}^{3} \cdot \mathrm{year}^{-1}\right)$ & 8.93 & 8.59 & 0.343 \\
& $\mathrm{R}^{2}$ & $0.969 *$ & $0.966^{*}$ & 0.420 \\
$2013-2019$ & Slope $\left(\mathrm{km}^{3} \cdot \mathrm{year}^{-1}\right)$ & 9.92 & 9.49 & 0.422 \\
& $\mathrm{R}^{2}$ & $0.842 *$ & $0.850^{*}$ & 0.300 \\
\hline
\end{tabular}

446

\section{$447 \quad 5.2$ RLV and lake area}

448 Figure 15 shows annual RLV trend slope by lake area. For most lakes in $1-10 \mathrm{~km}^{2}$, their RLV trend

449 slope is between 0 and $0.003 \mathrm{~km}^{3} / \mathrm{y}$, indicating slow increase in water volume in the past 30 years. As

450 lake area increases from $10-50 \mathrm{~km}^{2}$ to greater than $50 \mathrm{~km}^{2}$, RLV trend slopes also increased (Fig. 15C-

451 D) though the number of lakes reduced. Nevertheless, there are some exceptions. For example, there are

452 lakes with area larger than $100 \mathrm{~km}^{2}$ (Fig. 15D) but their RLV increasing rate is less than $0.003 \mathrm{~km}^{3} / \mathrm{y}$.

453 Some lakes with an area between $10-50 \mathrm{~km}^{2}$ have annual RLV larger than $0.01 \mathrm{~km}^{3} / \mathrm{y}$ (Fig. 15B). Some

454 small lakes, with an area less than $10 \mathrm{~km}^{2}$, have decreasing RLV rate smaller than $0.01 \mathrm{~km}^{3} / \mathrm{y}$ (Fig. 15A). 


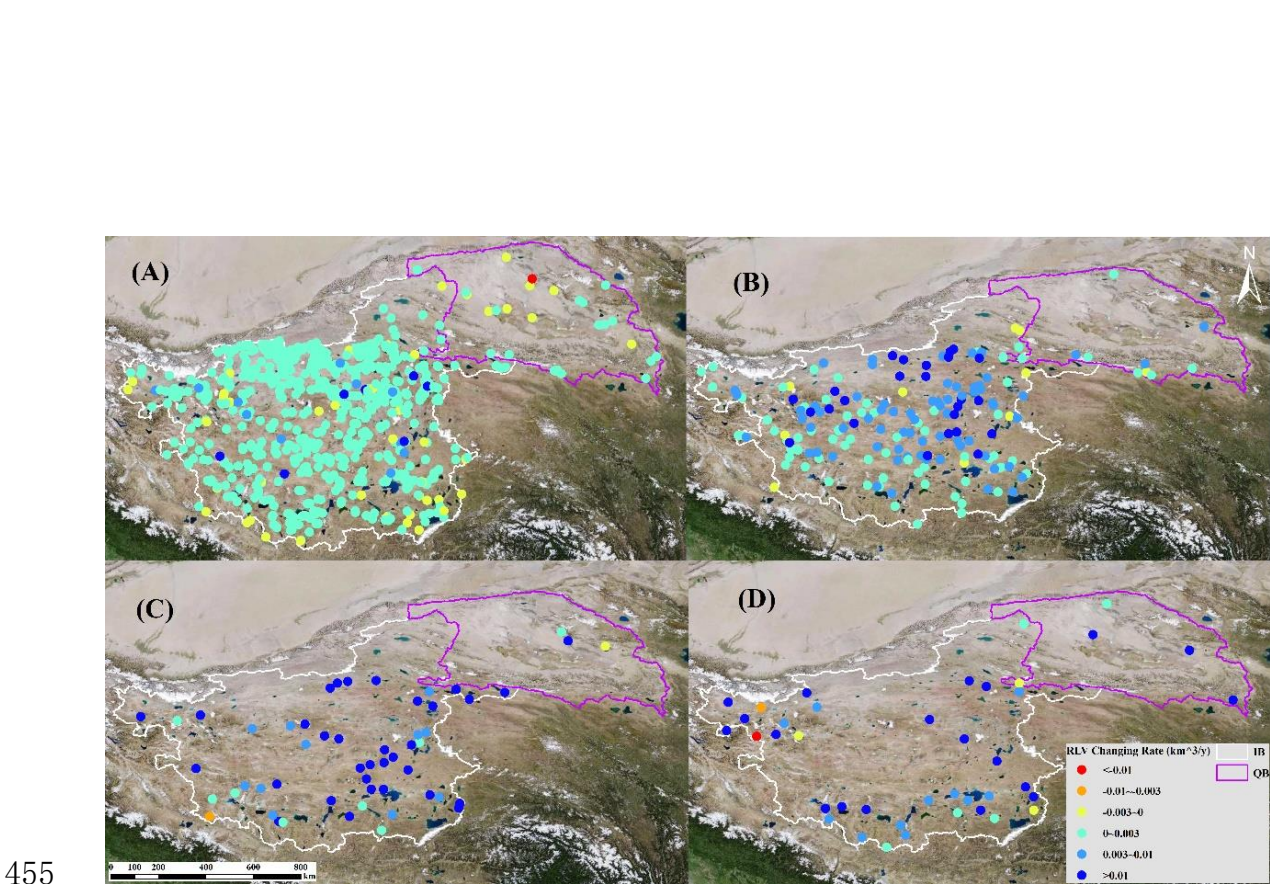

Figure 15: Annual RLV trend by lake area of (A) $1-10 \mathrm{~km}^{2}$, (B) $10-50 \mathrm{~km}^{2}$, (C) $50-100 \mathrm{~km}^{2}$, (D) $>100 \mathrm{~km}^{2}$. Background remote sensing image is from http://t0.tianditu.gov.cn/img_c/wmts.

Table 6 shows the statistics of annual RLV trend by lake area. In general, the larger the lake area, the greater the trend slope. The mean and standard deviation of the trend slopes both increase with the increase of area. The range of the RLV rate for lakes of $0-10 \mathrm{~km}^{2}$ is larger than that for lakes of $10-50$

Table 6: Statistics of annual RLV changing rate.

\begin{tabular}{|c|c|c|c|c|}
\hline \multirow{2}{*}{$\begin{array}{c}\text { Statistics of } \\
\text { Annual RLV changing rate }\end{array}$} & \multicolumn{4}{|c|}{ Lake Area } \\
\hline & $1-10 \mathrm{~km}^{2}$ & $10-50 \mathrm{~km}^{2}$ & $50-100 \mathrm{~km}^{2}$ & $>100 \mathrm{~km}^{2}$ \\
\hline Count & 675 & 175 & 56 & 70 \\
\hline $\operatorname{Minimum}\left(\mathrm{km}^{3} / \mathrm{y}\right)$ & -0.038 & -0.0014 & -0.0054 & -0.051 \\
\hline $\operatorname{Maximum}\left(\mathrm{km}^{3} / \mathrm{y}\right)$ & 0.037 & 0.037 & 0.085 & 1.04 \\
\hline Mean $\left(\mathrm{km}^{3} / \mathrm{y}\right)$ & 0.00068 & 0.0052 & 0.016 & 0.075 \\
\hline Standard Deviation $\left(\mathrm{km}^{3} / \mathrm{y}\right)$ & 0.0032 & 0.0059 & 0.015 & 0.15 \\
\hline
\end{tabular}

\section{Discussions}

468 Lake surface elevation can be estimated by calculating the average elevation of lake boundary (Bao et 469 al., 2005; Li et al., 2019; Yang et al., 2017a; Yao et al., 2018). This approach assumes that the DTM are 
471 (Takaku et al., 2014; Van Zyl, 2001) but our study period starts from 1989. As such, lake surface 472 elevation in this study is estimated based on the area-elevation relationship derived from the DTM. 473 Existing studies mainly used just one of a few methods, including linear equation (Yang et al., 2017b), 474 parabolic equation ( $\mathrm{Li}$ et al., 2019) or monotonic cubic spline fitting (Yao et al., 2018), in deriving lake elevation-area relationship. In this research, we compared those methods and used different methods under different situations (see Sect. 3.4). Four lakes, with area ranging from $0.97 \mathrm{~km}^{2}$ to $149.3 \mathrm{~km}^{2}$, were selected to explain the typical situations when different methods were used. Figure 16 shows the elevation-area pairs (red points) from the DTM and estimated elevations based on image lake area using different data fitting methods. For fitting the data from the DEM, MCI has the best fitting performance for the lakes in Fig. 16A \& B and there is no obvious disparities between SOPR and MCI in Fig. $16 \mathrm{C} \&$ D. The LR has the worst performance in Fig. 16 A, B \& C. However, when the elevation-area pairs from the DTM do not cover the lake area range from Landsat images, estimated elevation can have serious error, especially for MCI. Take the lake in

Fig. 16B as an example, its area range from Landsat imagery is $[0.23,16.71] \mathrm{km}^{2}$ from 1989 to 2019 , yet the smallest area obtained from SRTM is $4.69 \mathrm{~km}^{2}$. This is because the DTM were obtained after 2000 but most lakes had been expending since 1995 in the region. While MCI fits well with the elevation-area data from the DTM, elevations estimated outside the DTM area range are unreal in Fig. 16B \& D), especially in Fig. 16D, where the elevation estimates for lake area smaller than the smallest area from the DTM are unreasonably high. Those examples indicate that MCI may overfit and should only be used for lakes when their image area is within the area range from the DTM. SOPR predicted lake elevations generally follow the same trend when lake image area is outside DTM area range. As such, SOPR is selected when lake image area is smaller than the minimum area from the DTM. In addition to the above situations, the number of elevation-area pairs from the DTM within the area range of $[\mathrm{MinA} / 1.5$,

494 MaxA*1.5] also play a role as discussed in Sect. 3.4. Besides, some other situations also affect the choice 495 of the methods. When using SOPR method, the fitted curve is not monotonic if its symmetric axis falls into [MinA, MaxA] (Fig. 16A). When this happens, LR method was used instead. 

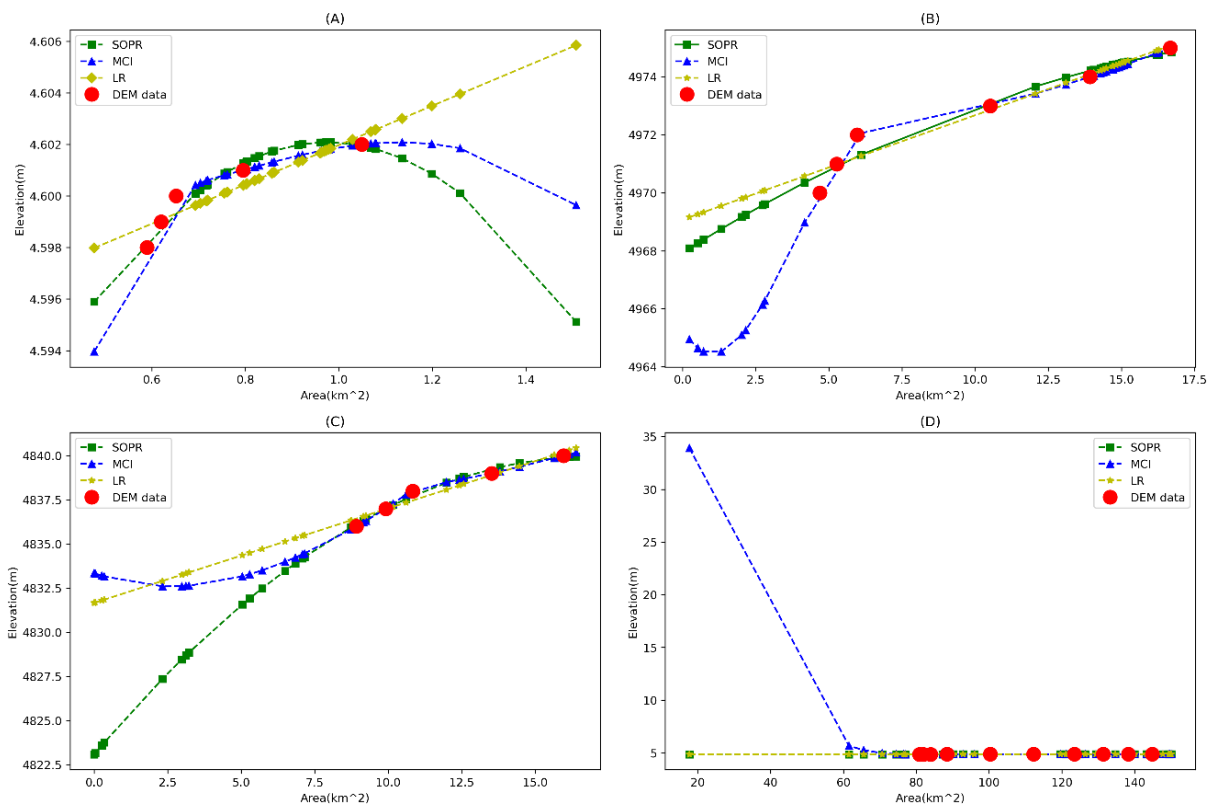

Figure 16: Estimated elevation based on image lake area using LR, SOPR and MCI. The elevation-area data pairs obtained from SRTM DEM is also added.

500 The number of lakes and the minimum, maximum, and average lake area for each method are listed in

501 Table 7. The most used method is SOPR with 766 lakes. While LRN and LRC are typically used for

502 small lakes, MCI is selected mostly for large lakes. Since MCI was only used for lakes when their image

503 area is within the area range from the DTM, this indicates most large lakes' area started increasing after

2000. In summary, we found no single method is suitable for all the lakes, and different methods have to

505 be used for different lakes.

506 Table 7: Frequency and lake area statistics for each method used in deriving the lake elevation-area relationship. Lake area is for 2019.

\begin{tabular}{ccccc}
\hline Methods & Frequency & $\begin{array}{c}\text { Minimum lake area } \\
\left(\mathbf{k m}^{\mathbf{2}}\right)\end{array}$ & $\begin{array}{c}\text { Maximum lake area } \\
\left(\mathbf{k m}^{\mathbf{2}}\right)\end{array}$ & $\begin{array}{c}\text { Average lake area } \\
\left(\mathbf{k m}^{\mathbf{2}}\right)\end{array}$ \\
\hline LRN & 24 & 0.049 & 27.35 & 3.40 \\
LRC & 30 & 0.86 & 9.72 & 2.30 \\
LRS & 75 & 0.028 & 1044.80 & 62.74 \\
SOPR & 766 & 0.049 & 1078.81 & 25.71 \\
MCI & 81 & 1.46 & 2016.52 & 121.83 \\
\hline
\end{tabular}




\subsection{RLV variation}

509 Although lakes with larger area usually have larger RLV trend slope, we found that the range of the change rates for the lakes in $1-10 \mathrm{~km}^{2}$ is larger than that for the lakes in $10-50 \mathrm{~km}^{2}$ in Sect. 4.2. Here

511 we further examined the relationship between lake area and the coefficient of variation (CV) of RLV

512 (Fig. 17). While there is lack of correlation between them, the percentages of lakes with $|\mathrm{CV}|>10$ in the

513 four area ranges are $3.7 \%, 2.3 \%, 1.8 \%$, and $2.9 \%$ respectively, with lakes in $1-10 \mathrm{~km}^{2}$ having the highest

514 ratio. The lakes with extreme RLV are mostly located in the peripheral of the IB and QB (Fig. 17).

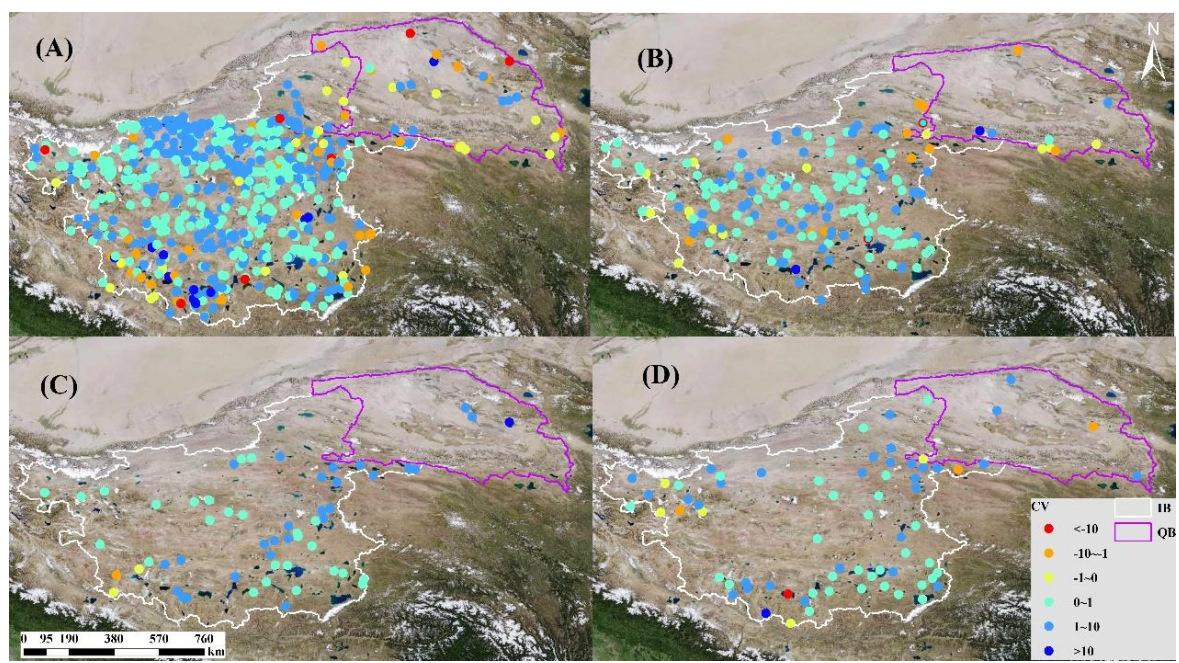

Figure 17: CV of annual RLV by lake area of (A) $1-10 \mathrm{~km}^{2}$, (B) $10-50 \mathrm{~km}^{2}$, (C) $50-100 \mathrm{~km}^{2},(\mathrm{D})>100 \mathrm{~km}^{2}$.

Background remote sensing image is from http://t0.tianditu.gov.cn/img_c/wmts.

The minimum, maximum and mean CV of all lakes are $-106.65,82.77$ and 0.89, respectively. And $94.36 \%$

(921 out of 976) of the lakes have a CV between -1 1, which indicates that the remaining few lakes have significant volume changes in the past 30 years. The annual lake area and RLV of the three lakes with the highest absolute CV are shown in Fig. 18. All three lakes have significant volume fluctuation in the past 30 years. For lake (1) (Fig. 18C(1)), its volume decreased significantly from 1994 to 1996 and increased rapidly from 2003 to 2009. For lake (2) (Fig. 19C(2)), its volume fluctuated cyclically in the past 30 years. From 1989 to 1996, its water volume had been continuously decreasing and reached the minimum RLV of $-0.0011 \mathrm{~km}^{3}$. From 1996 to 2004, its lake volume kept rising and reached the maximum RLV of $0.0026 \mathrm{~km}^{3}$. Subsequently, its volume started to decline again, reaching a minimum value of - 
https://doi.org/10.5194/essd-2021-331

Preprint. Discussion started: 12 November 2021

(c) Author(s) 2021. CC BY 4.0 License.

528 However, between 1990 and 2000, its volume fluctuated significantly. While all these example lakes are

529 in $1-10 \mathrm{~km}^{2}$ and have extreme CVs, their temporal variations are different indicating the influence of

530 local hydro-climatic factors on lake dynamics 

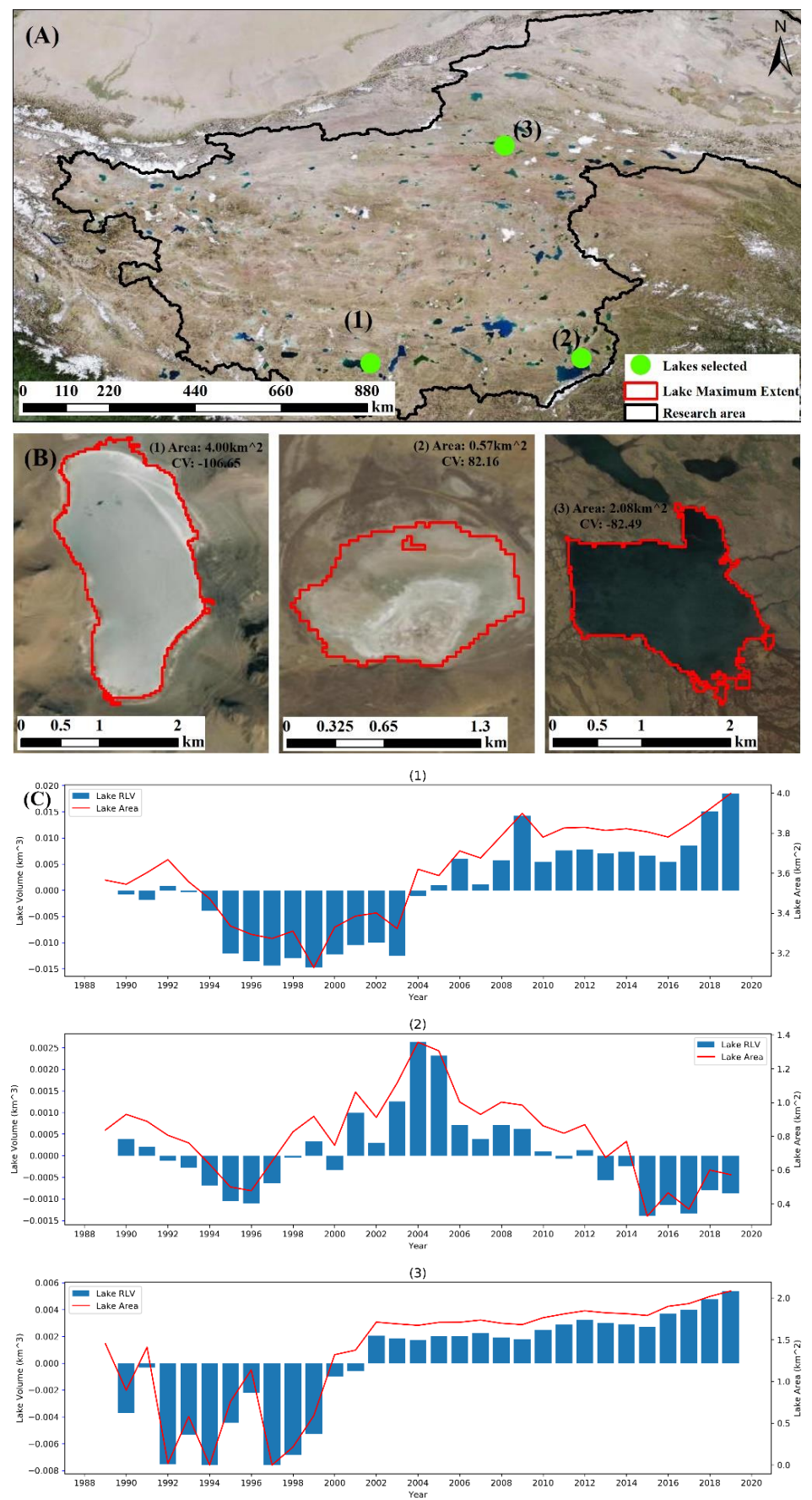

Figure 18: The location of three lakes with the highest absolute CV in the EBTP (A), their maximum extents (B) and area and RLV time series of the lakes (C). Remote sensing images in (A) and (B) are from http://t0.tianditu.gov.cn/img_c/wmts. 
536 In previous research, although some studies (Li et al., 2019; Zhang et al., 2020; Dong et al., 2018) have

537 found that lakes of different sizes respond differently to climate change, there is a lack of attention to

538 lakes less than $10 \mathrm{~km}^{2}$. This is mainly due to insufficient data of small lakes in the region. Our results

539 indicate that small lakes are important as lakes with higher CV are usually less than $10 \mathrm{~km}^{2}$, which, however, is different from the definition of small lakes in Zhang et al. (2020) (50-100 $\left.\mathrm{km}^{2}\right)$ and Dong et al. (2018) (10-30 $\left.\mathrm{km}^{2}\right)$. Our results show that lakes less than $10 \mathrm{~km}^{2}$ are more prone to drastic volume change and should receive more attention. In addition, most existing data products focused on lake area instead of volume change, though RLV is more valuable in studying water balance in hydrological systems.

546 This research provides a comprehensive census on water volume change for the lakes greater than or

547 equal to $1 \mathrm{~km}^{2}$ in the EBTP from 1989-2019 using Landsat imagery and DTM data. Our annual dataset,

548 compared with satellite altimetry and other existing data, covers more lakes, especially small lakes in 1

$549-10 \mathrm{~km}^{2}$, and longer time period.

550 The comparison with three other major existing data products indicates that our dataset is reliable and might be more accurate. To the best of our knowledge, our dataset provides the longest and most

552 comprehensive lake water volume change data in the region, especially for small lakes $\left(1-10 \mathrm{~km}^{2}\right)$. The

553 dataset is valuable in studying the impacts of climate change and water balance in the region.

554 Our research indicates that small lakes with an area in $1-10 \mathrm{~km}^{2}$ are most sensitive and have the highest fluctuation in water volume in the study time period. Monitoring their changes is of critical importance for understanding regional and global climate change. In deriving the lake area-elevation relationship from DTM, the best result comes from the combination of several data fitting methods. The workflow used in this research can be further developed to process individual remote sensing image (instead of annual composite image) and create a lake volume dataset with a higher temporal resolution in future research. 

endorheic basin of the Tibetan Plateau (EBTP) during 1989-2019 using Landsat imagery and digital terrain models. This dataset consists of two lake extents shapefiles containing the annual area and relative volume data from 1989 to 2019 for each lake. In addition, the lake seeds used to identify the lakes are also included as a shapefile in this dataset. The dataset (https://doi.org/10.5281/zenodo.5543615, Wang et al., 2021), entitled "Lake area and volume variation data in the endorheic basin of the Tibetan Plateau from 1989 to 2019”, is available on Zenodo.

\section{Author contribution}

570 Conceptualization, L.Z. and X.L.; methodology, L.W., X.L.; software, M.L.; validation, L.W., M.L. and

571 J.W.; formal analysis, M.L.; investigation, L.W.; resources, J.W.; writing—original draft preparation,

572 L.W.; writing — review and editing, J.W.; visualization, M.L.; supervision, X.L.; project administration,

573 J.W.; funding acquisition, L.Z. All authors have read and agreed to the published version of the 574 manuscript.

\section{$575 \quad$ Competing interests}

576 The authors declare that they have no conflict of interest.

\section{Acknowledgements} of Natural Resources No. 2019CZEPK01.

\section{References}

584 Bao, P., Zhang, L., and Wu, X.: Canny edge detection enhancement by scale multiplication, IEEE 

Landsat 8 OLI multispectral data, International Journal of Remote Sensing, 39, 3646 -3678, 2018. Boos, W. R. and Kuang, Z.: Dominant control of the South Asian monsoon by orographic insulation versus plateau heating, Nature, 463, 218-222, 2010.

Chen, C., Twycross, J., and Garibaldi, J. M.: A new accuracy measure based on bounded relative error for time series forecasting, PloS one, 12, e0174202, 2017

592 Crétaux, J.-F., Abarca-del-Río, R., Berge-Nguyen, M., Arsen, A., Drolon, V., Clos, G., and Maisongrande, P.: Lake volume monitoring from space, Surveys in Geophysics, 37, 269-305, 2016. Crétaux, J.-F., Jelinski, W., Calmant, S., Kouraev, A., Vuglinski, V., Bergé-Nguyen, M., Gennero, M. C., Nino, F., Del Rio, R. A., and Cazenave, A.: SOLS: A lake database to monitor in the Near Real Time water level and storage variations from remote sensing data, Advances in space research, 47, 1497-1507, 2011.

598 Cristóbal, J., Jiménez-Muñoz, J., Sobrino, J., Ninyerola, M., and Pons, X.: Improvements in land surface temperature retrieval from the Landsat series thermal band using water vapor and air temperature, Journal of Geophysical Research: Atmospheres, 114, 2009.

601 Donchyts, G., Baart, F., Winsemius, H., Gorelick, N., Kwadijk, J., and Van De Giesen, N.: Earth's surface water change over the past 30 years, Nature Climate Change, 6, 810, 2016. Dong, S., Peng, F., You, Q., Guo, J., and Xue, X.: Lake dynamics and its relationship to climate change on the Tibetan Plateau over the last four decades, Regional environmental change, 18, 477-487, 2018. extraction techniques using Landsat ETM+ data: case study Aswan High Dam Lake (AHDL), Procedia Technology, 22, 1205-1212, 2016. Field, C. B.: Climate change 2014-Impacts, adaptation and vulnerability: Regional aspects, Cambridge University Press, 2014.

611 Gao, B.-C.: NDWI—A normalized difference water index for remote sensing of vegetation liquid 612 water from space, Remote sensing of environment, 58, 257-266, 1996.

613 Gorelick, N., Hancher, M., Dixon, M., Ilyushchenko, S., Thau, D., and Moore, R.: Google Earth Engine: 614 Planetary-scale geospatial analysis for everyone, Remote sensing of Environment, 202, 18-27, 6152017

616 Gray, D. K., Hampton, S. E., O'Reilly, C. M., Sharma, S., and Cohen, R. S.: How do data collection 617 and processing methods impact the accuracy of long-term trend estimation in lake surface-water 618 temperatures?, Limnology and Oceanography: Methods, 16, 504-515, 2018.

619 Hansen, J., Ruedy, R., Sato, M., and Lo, K.: Global surface temperature change, Reviews of 620 Geophysics, 48, 2010.

621 Huang, H., Chen, Y., Clinton, N., Wang, J., Wang, X., Liu, C., Gong, P., Yang, J., Bai, Y., and Zheng, 622 Y.: Mapping major land cover dynamics in Beijing using all Landsat images in Google Earth Engine, 623 Remote Sensing of Environment, 202, 166-176, 2017.

624 Hwang, C., Cheng, Y.-S., Yang, W.-H., Zhang, G., Huang, Y.-R., Shen, W.-B., and Pan, Y.: Lake level 625 changes in the Tibetan Plateau from Cryosat-2, SARAL, ICESat, and Jason-2 altimeters, Terr. Atmos. 

variations on the Tibetan Plateau using CryoSat-2 SARIn mode data, Journal of Hydrology, 544, 109-124, 2017. Junxiao, W., Liuming, W., Mengyao, L., Liping, Z., and Xingong L.: Lake area and volume variation data in the endorheic basin of the Tibetan Plateau from 1989 to 2019 [Data set], https://doi.org/10.5281/zenodo.5543615, 2021. Zhang, G.: Lake seasonality across the Tibetan Plateau and their varying relationship with regional mass changes and local hydrology, Geophysical Research Letters, 44, 892-900, 2017. ON ICESAT AND ENVISAT DATA SERIES, International Archives of the Photogrammetry, Remote Sensing \& Spatial Information Sciences, 42, 2017. Li, J. and Narayanan, R. M.: A shape-based approach to change detection of lakes using time series remote sensing images, IEEE transactions on geoscience and remote sensing, 41, 2466-2477, 2003. Li, X., Long, D., Huang, Q., Han, P., Zhao, F., and Wada, Y.: High-temporal-resolution water level and storage change data sets for lakes on the Tibetan Plateau during 2000-2017 using multiple altimetric missions and Landsat-derived lake shoreline positions, Earth System Science Data Discussions, 11, 1603-1627, 2019. Liu, J., Wang, S., Yu, S., Yang, D., and Zhang, L.: Climate warming and growth of high-elevation inland lakes on the Tibetan Plateau, Global and Planetary Change, 67, 209-217, 2009. Ma, R., Duan, H., Hu, C., Feng, X., Li, A., Ju, W., Jiang, J., and Yang, G.: A half-century of changes in China's lakes: Global warming or human influence?, Geophysical Research Letters, 37, 2010.

Otsu, N.: A threshold selection method from gray-level histograms, IEEE transactions on systems, man, and cybernetics, 9, 62-66, 1979.

Pekel, J.-F., Cottam, A., Gorelick, N., and Belward, A. S.: High-resolution mapping of global surface water and its long-term changes, Nature, 540, 418-422, 2016. their links to climate change throughout the Tibetan Plateau, Remote Sensing of Environment, 222 232-243, 2019.

Qiu, J.: China: the third pole, Nature News, 454, 393-396, 2008.

Rokni, K., Ahmad, A., Selamat, A., and Hazini, S.: Water feature extraction and change detection using multitemporal Landsat imagery, Remote sensing, 6, 4173-4189, 2014. Setiawan, B. D., Rusydi, A. N., and Pradityo, K.: Lake edge detection using Canny algorithm and Otsu thresholding, 2017, 72-76. Tibetan Plateau: Detection and analysis by integrating satellite altimetry and optical imagery, Hydrological Processes, 28, 2411-2418, 2014.

664 Song, C., Sheng, Y., Ke, L., Nie, Y., and Wang, J.: Glacial lake evolution in the southeastern Tibetan 665 Plateau and the cause of rapid expansion of proglacial lakes linked to glacial-hydrogeomorphic processes, Journal of hydrology, 540, 504-514, 2016. 
669 Geomorphology, 280, 30-38, 2017.

670 Takaku, J., Tadono, T., and Tsutsui, K.: GENERATION OF HIGH RESOLUTION GLOBAL DSM FROM

671 ALOS PRISM, ISPRS Annals of Photogrammetry, Remote Sensing \& Spatial Information Sciences,

$672 \quad 2,2014$.

673 Van Zyl, J. J.: The Shuttle Radar Topography Mission (SRTM): a breakthrough in remote sensing of

674 topography, Acta Astronautica, 48, 559-565, 2001.

675 Wan, W., Long, D., Hong, Y., Ma, Y., Yuan, Y., Xiao, P., Duan, H., Han, Z., and Gu, X.: A lake data set

676 for the Tibetan Plateau from the 1960s, 2005, and 2014, Scientific data, 3, 160039, 2016.

677 Weekley, D. and Li, X.: Tracking multidecadal lake water dynamics with Landsat imagery and 678 topography/bathymetry, Water Resources Research, 55, 8350-8367, 2019.

679 Williamson, C. E., Saros, J. E., Vincent, W. F., and Smol, J. P.: Lakes and reservoirs as sentinels, 680 integrators, and regulators of climate change, Limnology and Oceanography, 54, 2273-2282, 2009.

681 Xu, Z., Gong, T., and Li, J.: Decadal trend of climate in the Tibetan Plateau-regional temperature

682 and precipitation, Hydrological Processes: An International Journal, 22, 3056-3065, 2008.

683 Yang, K., Yao, F., Wang, J., Luo, J., Shen, Z., Wang, C., and Song, C.: Recent dynamics of alpine lakes 684 on the endorheic Changtang Plateau from multi-mission satellite data, Journal of Hydrology, 552, 685 633-645, 2017a.

686 Yang, R., Zhu, L., Wang, J., Ju, J., Ma, Q., Turner, F., and Guo, Y.: Spatiotemporal variations in volume 687 of closed lakes on the Tibetan Plateau and their climatic responses from 1976 to 2013, Climatic 688 change, 140, 621-633, 2017b.

689 Yao, F., Wang, J., Yang, K., Wang, C., Walter, B. A., and Crétaux, J.-F.: Lake storage variation on the 690 endorheic Tibetan Plateau and its attribution to climate change since the new millennium, 691 Environmental Research Letters, 13, 064011, 2018.

692 Zhang, G., Yao, T., Piao, S., Bolch, T., Xie, H., Chen, D., Gao, Y., O'Reilly, C. M., Shum, C., and Yang, 693 K.: Extensive and drastically different alpine lake changes on Asia's high plateaus during the past 694 four decades, Geophysical Research Letters, 44, 252-260, 2017a.

695 Zhang, G., Yao, T., Shum, C., Yi, S., Yang, K., Xie, H., Feng, W., Bolch, T., Wang, L., and Behrangi, A.:

696 Lake volume and groundwater storage variations in Tibetan Plateau's endorheic basin, Geophysical

697 Research Letters, 44, 5550-5560, 2017b.

698 Zhang, Y., Zhang, G., and Zhu, T.: Seasonal cycles of lakes on the Tibetan Plateau detected by 699 Sentinel-1 SAR data, Science of The Total Environment, 703, 135563, 2020.

700 Zhou, J., Wang, L., Zhang, Y., Guo, Y., Li, X., and Liu, W.: Exploring the water storage changes in the 701 largest lake (Selin Co) over the T ibetan P lateau during 2003-2012 from a basin-wide hydrological 702 modeling, Water Resources Research, 51, 8060-8086, 2015. 